\title{
Investigation of Dosimetry in Four Human Head Models for Planar Monopole Antenna with a Coupling Feed for LTE/WWAN/ WLAN Internal Mobile Phone
}

\author{
L. Belrhiti, F. Riouch, A. Tribak \\ STRS Laboratory, National Institute of Posts and Telecommunications -INPT, Rabat, Morocco \\ E-mail: \{belrhiti,riouch,tribak\}@inpt.ac.ma \\ J. Terhzaz \\ Centre régional des métiers de l'éducation et de la formation (CRMEF), Casablanca, Morocco \\ E-mail:terhzazj@yahoo.fr \\ Angel Mediavilla Sanchez \\ DICOM, University of Cantabria, Santander, Spain, angel.mediavilla@unican.es
}

\begin{abstract}
The objective of the present study is to evaluate the Specific Absorption Rate (SAR) within the human head model exposed to the radiation of planar monopole antenna with $\mathrm{T}$-shaped coupling feed and an inductive shorting strip. The presented design has a compact structure, a planar configuration and occupying a small size of $36 \times 20 \mathrm{~mm}^{2}$. Two wide bands can be generated by the proposed antenna $546 \mathrm{MHz}(734-1280 \mathrm{MHz})$ and $1066 \mathrm{MHz}(1934-$ $3000 \mathrm{MHz}$ ) for the LTE/WWAN/WLAN internal mobile phone. The antenna performance parameters comprising return loss, radiation patterns, and gain are discussed. In this research work four different human head models have been implemented: homogenous spherical head, spherical seven layer model, Specific Anthropomorphic Mannequin (SAM) phantom and HUGO human head model. On the other hand the effects of operating frequency and gap distance between the mobile phone antenna and the human head model on distributions of the SAR inside the human head are investigated. All the simulations are done for three different distances between the antenna and the head model $(5 \mathrm{~mm}, 10 \mathrm{~mm}$ and $20 \mathrm{~mm}$ ). Moreover, the SAR levels for the head tissues are calculated in accordance to the two currently accepted standards: Federal Communications Commission (FCC) and International Commission on Non-Ionizing Radiation Protection (ICNIRP).
\end{abstract}

Index Terms - Mobile phone, human head model, Specific Absorption Rate (SAR) ,LTE/WWAN/WLAN, FCC, ICNIRP, Specific Anthropomorphic Mannequin (SAM), HUGO human head model.

\section{INTRODUCTION}

The antennas used for mobile telephony have experienced well recess of transformations to adapt to the needs of the market. These improvements are continuing to perfect parallel to the deployment of $2 \mathrm{G}$ standards, $2.5 \mathrm{G}, 3 \mathrm{G}$ and $4 \mathrm{G}$. The demands placed on mobile communication systems have increased remarkably. Moreover, the antennas need to have, small physical size, low or ultra-low- 
profile features, wide or ultra-wide operating bandwidth, multiple functions, high gain, high efficiency, pure polarization, and low cost, etc. [1].

Recently, some promising internal antennas for mobile phone applications are capable of covering the GSM 850,GSM 900,DCS 1800, PCS 1900, UMTS bands (824-896, 880-960,1710-1880,18501990,1920-2170 MHz) and the LTE 700, LTE 2300, LTE 2500 bands (698-787,2305-2400,2500$2690 \mathrm{MHz}$ ) for WWAN/LTE operations. As reported in [2], a coupled-fed planar printed antenna for LTE/WWAN mobile phone applications using the technique slotted ground structure is presented. The antenna has a small size of only $15 \times 50 \mathrm{~mm}^{2}$ and capable of generating two wide operating bands $698-960 \mathrm{MHz}$ and $1710-2690 \mathrm{MHz}$. The authors proposed in [3] a multi-resonant antenna embedding two inductors in radiating strips for eight-band LTE/WWAN operation, this antenna consists of two chip-inductor-loaded feeding strip and coupling strip.

The Specific Absorption Rate (SAR) is a defined parameter for evaluating the power absorption in human tissue [4].For the cellular phone compliance [5], the SAR value must not exceed the exposure guidelines [6,7]. The SAR limit specified in the IEEE C95.1: 1999 standard is $1.6 \mathrm{~W} / \mathrm{Kg}$ in a $1 \mathrm{~g}$ averaging mass, while that specified in the IEEE C95.1: 2005 standard has been updated to $2 \mathrm{~W} / \mathrm{Kg}$ in a $10 \mathrm{~g}$ averaging mass [6]. This new SAR limit specified in IEEE C95.1: 2005 is comparable to the limit specified in the International Commission on Non-Ionizing Radiation Protection (ICNIRP) guidelines [7] in Europe, Japan, Brazil and New Zealand. In general, the SAR value is influenced by various parameters such as antenna positions relative to the human body, radiation patterns of the antenna, radiated power and antenna types [8].

During the last years, many studies have discussed the evaluation of the SAR in human heads, as a function of the complexity and large scale involved in this type of problem [9,10].Recently, much attention have been devoted to the reduction of peak SAR in human head for mobile phone applications. So, different methods and techniques have been proposed to reduce SAR levels in human tissue, such as increasing the distance between the human head and the mobile handset antenna, auxiliary antenna elements, ferrite material, the electromagnetic band-gap (EBG) structures, artificial magnetic conductors (AMCs) surfaces, and metamaterials. As reported in [11,12], the effect of varying the distance between the antenna and user head has been investigated for a PIFA handset antenna, this study has shown that there is a proportional relation between SAR and antenna efficiency.

Furthermore, the researchers have investigated the effects of attaching particular materials to the antenna or mobile phones in order to reduce the peak SAR in human head. In [13,14], J. Wang, O. Fujiwara and T. Takagi discussed the effect of ferrite sheet attachment to mobile handset on the SAR reduction in human head. It is found that a reduction over $13 \%$ for the spatial peak SAR over $1 \mathrm{~g}$ averaging was achieved. On the other hand, the electromagnetic bandgap (EBG) structures are used for SAR reduction $[15,16]$. In article [15], an optimized multilayer PIFA with the EBG structure is 
introduced, the results show that the human head can be protected from hazardous EM fields using the EBG structure. As demonstrated in [17], the EBG technique reduces the antenna SAR up to $75 \%$.

The aim of this work is to examine the effects of electromagnetic radiation measured in terms of specific absorption rate (SAR) in a human head exposed to the radiation of a planar monopole antenna with a coupling feed and an inductive shorting strip for LTE/WWAN/WLAN internal mobile phone. Detailed design considerations and radiation caracteristics of the proposed antenna are also described in this paper .Four human head models were used: homogeneous spherical head consisting of a glass shell and a sphere as the tissue equivalent materials, for the second model is a spherical seven layer head model. The seven layers are Skin, Fat, Muscle, Skull, Dura, CSF (Cerebro Spinal Fluid) and Brain. The third model is a Specific Anthropomorphic Mannequin (SAM) phantom head provided by CST MWS, which is composed of two layers namely shell and fluid. The fourth model is a HUGO human head model also provided by CST MWS and consists of fifteen types of tissues. The SAR is systematically evaluated at various frequencies and for three different distances $(5 \mathrm{~mm}, 10 \mathrm{~mm}$ and $20 \mathrm{~mm}$ ) between the proposed antenna and the human head models. The whole work of this paper used Ansoft HFSS software and CST MWS to run all simulations and to calculate the SAR values.

\section{ANTENNA DESIGN AND CONFIGURATION}

Fig.1 shows the configuration and dimensions of the planar monopole antenna with a T-shaped coupling feed and an inductive shorting strip for LTE/WWAN/WLAN operation in the internal mobile phone. The geometry of the proposed antenna is presented in Fig.1. The antenna is formed by a T-Shaped driven strip, a radiating plate which is excited by using capacitive coupling feed technique and a meandered strip line with narrow width of $0.5 \mathrm{~mm}$ which is used as an inductive shorting strip. In this research work, the developed antenna is fabricated on an FR4 substrate of thickness $\mathrm{h}=1.6 \mathrm{~mm}$ with relative permittivity 4.4 , loss tangent 0.02 and size of $36 \times 120 \mathrm{~mm}^{2}$ was used as the system circuit board. The antenna is printed on the top ungrounded portion with a small size of

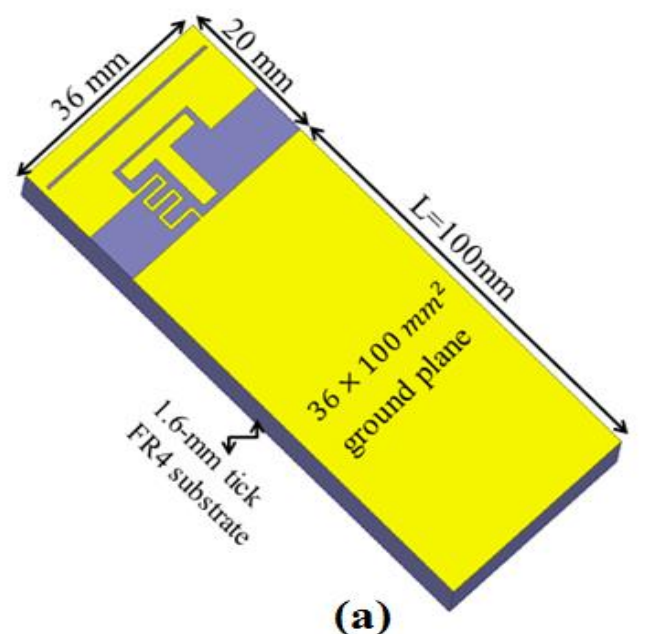

(a)

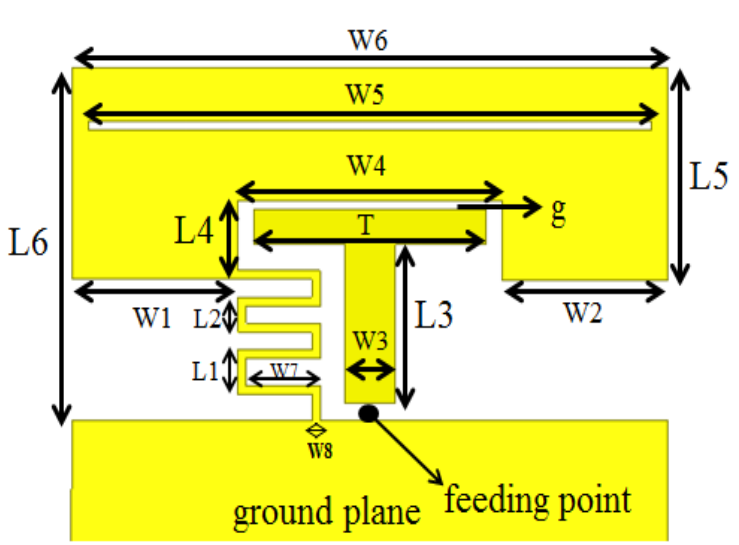

(b)

Fig. 1. (a) Geometry of the planar antenna with a coupling feed and an inductive shorting strip for LTE/WWAN/WLAN operation in the internal mobile phone, (b) the metal pattern of the antenna . 
$36 \times 20 \mathrm{~mm}^{2}$ and a ground plane of length $100 \mathrm{~mm}$ and width $36 \mathrm{~mm}$ is printed on the front side of the circuit board. The proposed antenna is optimized using a full-wave electromagnetic (EM) simulator, Computer Simulation Technology Microwave Studio CST MWS. The final design parameters are summarised as follows (units in $\mathrm{mm}$ ): $\mathrm{L} 1=2.5, \mathrm{~L} 2=2, \mathrm{~L} 3=9, \mathrm{~L} 4=4.5, \mathrm{~L} 5=12, \mathrm{~L} 6=20, \mathrm{~L}=100, \mathrm{~W} 1=10$, $\mathrm{W} 2=10, \mathrm{~W} 3=3, \mathrm{~W} 4=16, \mathrm{~W} 5=34, \mathrm{~W} 6=36, \mathrm{~W} 7=4.5, \mathrm{~W} 8=0.5, \mathrm{~g}=0.5, \mathrm{~T}=14$.

In this section, we begin by evaluating the performance of our proposed antenna by simulation using CST MWS software which is based on Finite Integration Technique (FIT). Fig. 2 shows the simulated return loss of the proposed antenna, the case with a direct feed and a simple shorting strip (Case1), the case with a T-shaped coupling feed without a simple shorting strip (Case2) and the case with a T-shaped coupling feed and a simple shorting strip (Case3). Notice that these three cases (Case1, Case2 and Case3) are developed in order to obtain the optimized geometric of the proposed antenna. All the corresponding dimensions of the three antennas analyzed in the figure are the same as those of the proposed antenna. The results obtained from Fig. 2 indicate that there is only one resonant mode at around $1.8 \mathrm{GHz}$ for Case 1 with a bandwidth of $360 \mathrm{MHz}$. As can be seen from the simulated results a much wider bandwidth for Case 2 than for Case 1 is obtained .By adding a simple shorting strip another resonant mode appeared in Case 3 at around $1.16 \mathrm{GHz}$ compared to Case2. It is clearly observed that two wide bands are generated in the case Case 3 with respect to the case Case 2 . The first resonant mode in Case 3 is shifted to around $1 \mathrm{GHz}$ for the proposed antenna and another mode is generated by replacing the simple shorting strip by an inductive shorting strip .By comparing the proposed antenna and Case3, the desired lower and upper bands are achieved by using the proposed antenna. Noted that the resonant mode at about $2.8 \mathrm{GHz}$ is obtained by inserting a slot with a width of $0.5 \mathrm{~mm}$ and a length of $34 \mathrm{~mm}$ in the radiating plate of the proposed antenna.
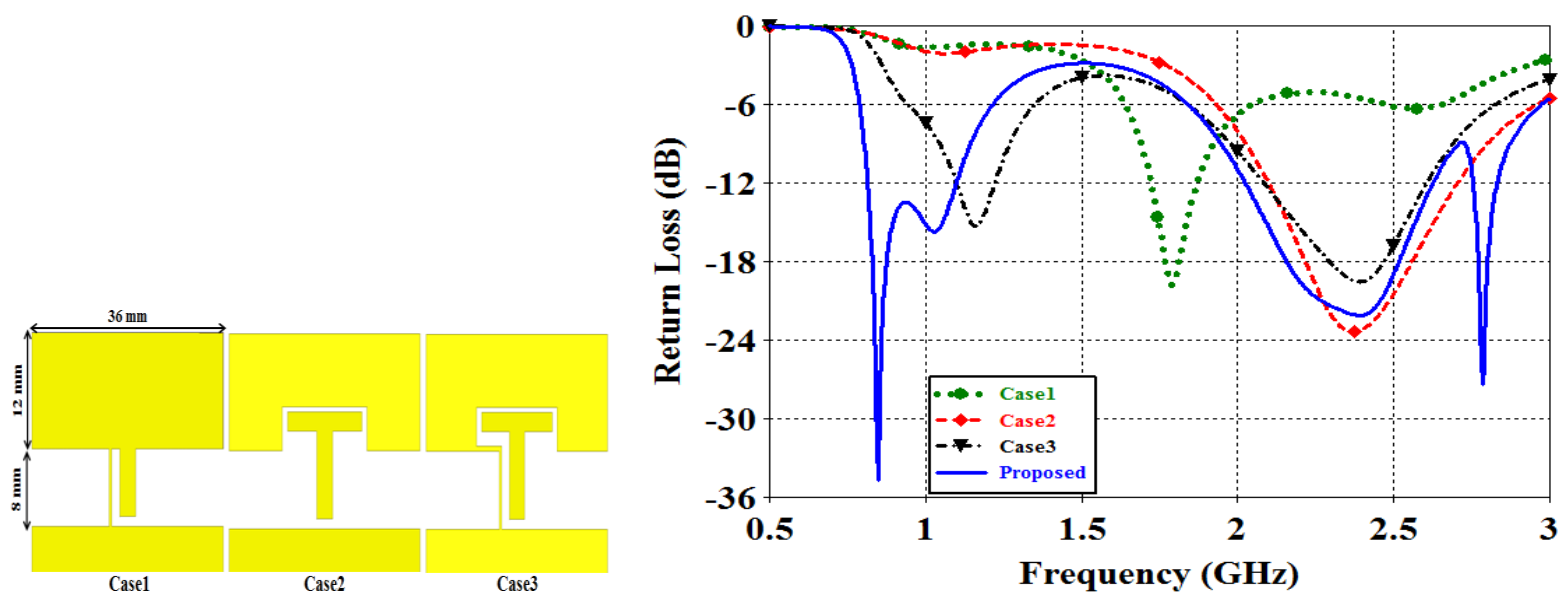

Fig. 2. Simulated return loss for the proposed antenna,Case1,Case2 and Case3.

A parametric study of important parameters of the proposed antenna are also investigated and analyzed in this work. Effects of the length $\mathrm{T}$ of the T-shaped driven strip are shown in Fig.3(a). Results for the length $\mathrm{T}$ varied from 14 to $30 \mathrm{~mm}$ are presented. It is found that large effects on both 
the antenna's lower and upper bands are seen. For the length $T(T=14)$, the two wide bands are strongly controlled. Fig.3(b) shows three various gaps between the T-shaped and coupled radiating plate, the other dimensions are the same as given in Fig.1. It can be observed that if the antenna works with the gap $\mathrm{g}=0.5 \mathrm{~mm}$, better impedance matching can be obtained both in the antenna's lower and upper bands.

Fig. 4(a) plots the simulated return loss as a function of the length W1, the other dimensions are the same as given in Fig. 1. Results for the length W1 varied from 2 to $10 \mathrm{~mm}$ are presented in Fig. 4(a). Large effects on the impedance matching of the antenna's lower band are seen. Also some effects of the upper band are shown. The $\mathrm{W} 1=10 \mathrm{~mm}$ is a good choice for our antenna design. The simulated return loss for the proposed antenna relative to the change in the width $\mathrm{W} 3$ varied from 1 to $3 \mathrm{~mm}$ are investigated in Fig. 4(b). The resonant modes of the lower band are not affected by the parameter W3, but large effects on the upper band are seen, for the $\mathrm{W} 3=3 \mathrm{~mm}$ wide impedance matching is observed in Fig. 4(b).

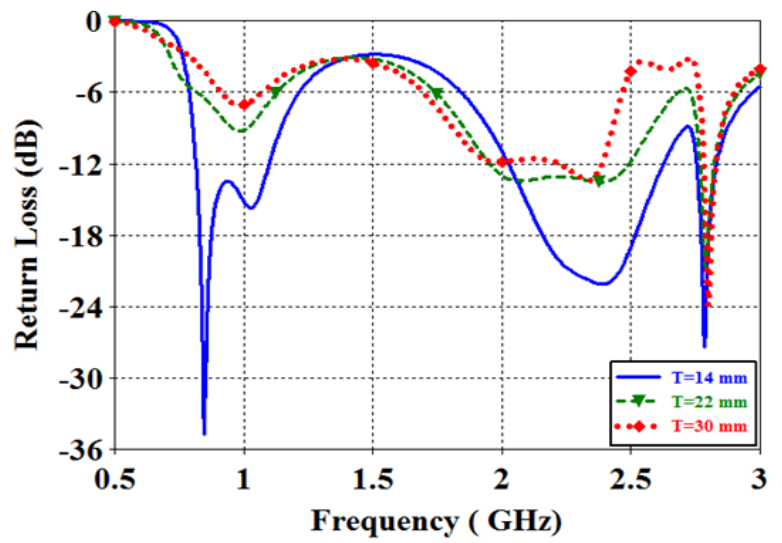

(a)

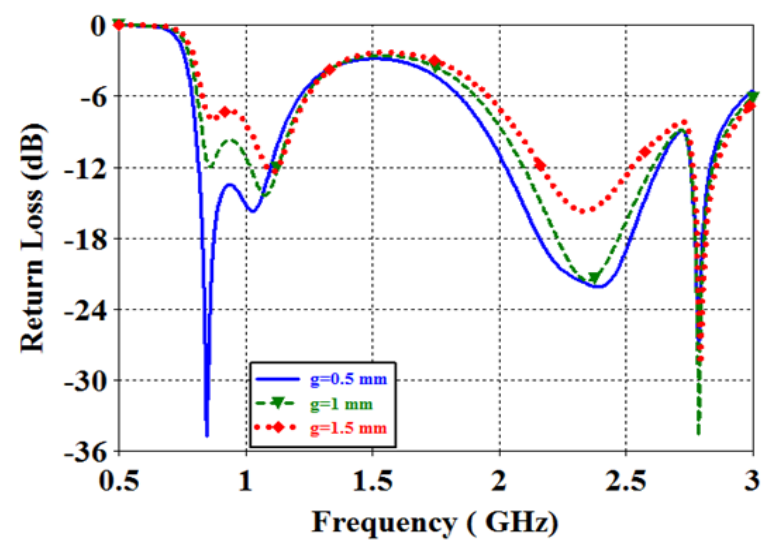

(b)

Fig .3. Simulated return loss as a function of (a) the length $\mathrm{T}$ and (b) the coupling gap g.

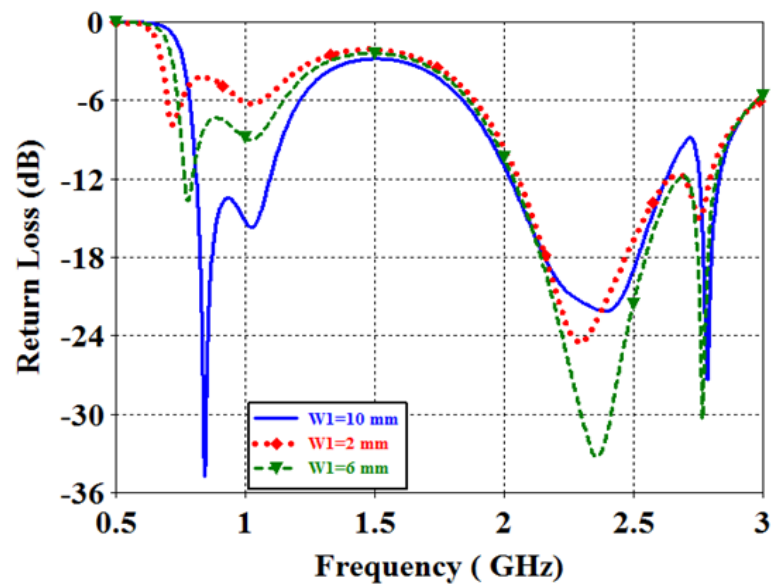

(a)

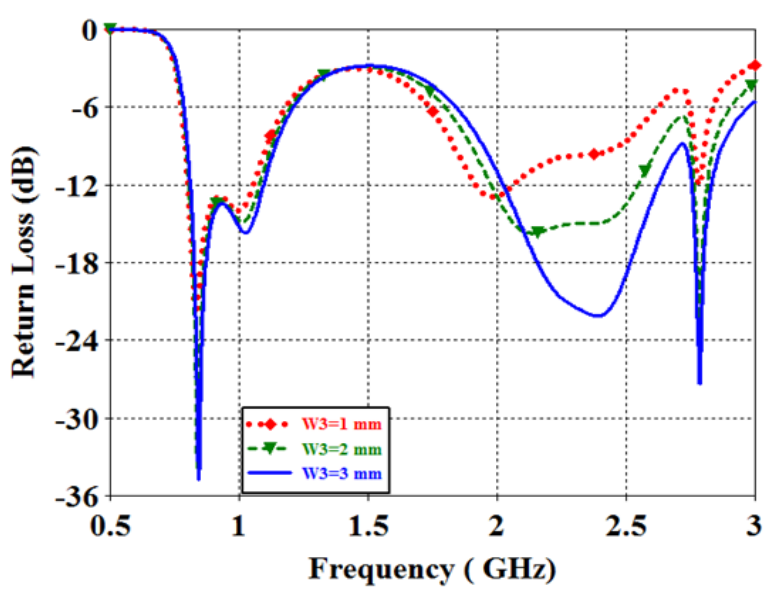

(b)

Fig. 4. Simulated return loss as a function of (a) the length W1 and (b) the width W3.

The effects of the system ground plane length $\mathrm{L}$ on the performances of the proposed antenna are also investigated. Fig.5 plots the simulated return loss for the proposed antenna as a function of the 
length $\mathrm{L}$ varied from 70 to $100 \mathrm{~mm}$. Large effects on both the antenna's lower and upper bands are seen. In this design, the preferred length $\mathrm{L}$ is determined to be $100 \mathrm{~mm}$ from the obtained results.

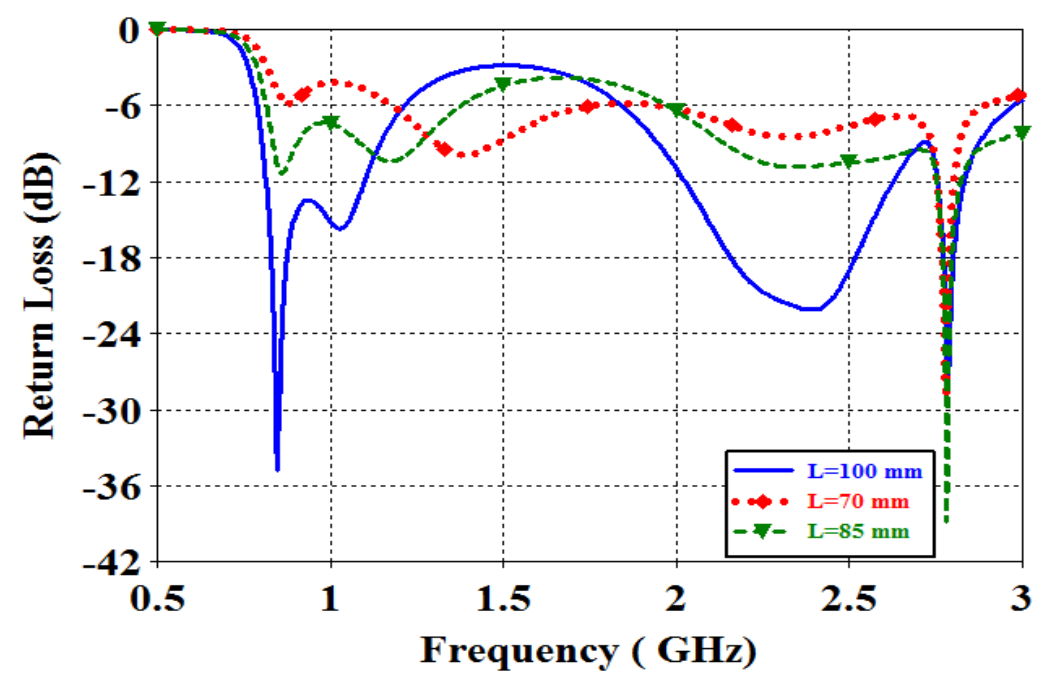

Fig. 5. Simulated return loss as a function of the length $\mathrm{L}$ of the main ground. Other dimensions are the same as in Fig. 1.

\section{SIMULATED AND EXPERIMENTAL RESULTS}

The compact planar monopole with a coupling feed and an inductive shorting strip, for LTE/WWAN/WLAN internal mobile phone, was successfully fabricated and tested. Fig. 6 shows the photograph of the fabricated monopole antenna.The proposed antenna was simulated and measured. The measured and simulated return loss curves for the constructed prototype are illustrated in Fig.7. The simulated results of CST MWS are compared with the Ansoft High Frequency Structure Simulator HFSS which is based on Finite Element Method (FEM), whereas the measured results are
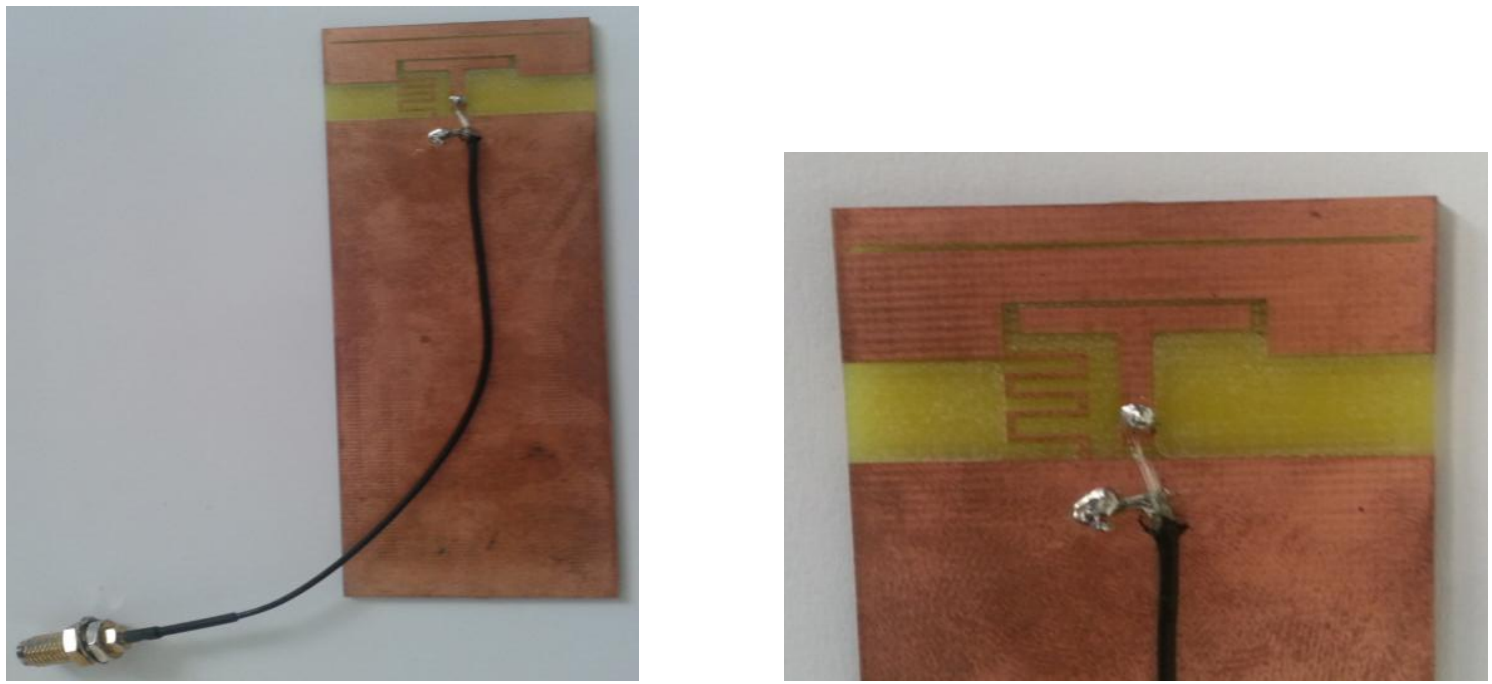

Fig.6. Photograph of the fabricated proposed antenna with the optimized geometric parameters.

tested by using the Anritsu Vector Network Analyzer Master MS2028C. We can also find that a good agreement between the measured data and simulated results is obtained. In all results the bandwidth is defined by 3:1 VSWR or -6dB return loss, which is generally acceptable for practical mobile phone 
antennas .From the measured results it is clearly observed that the antenna is capable of generating two wide operating bands, the lower band has a bandwidth of $546 \mathrm{MHz}(734-1280 \mathrm{MHz})$ which covers GSM850/GSM900, while the upper band has $1066 \mathrm{MHz}(1934-3000 \mathrm{MHz})$ which covers PCS1900/ UMTS2100/LTE2300/LTE2500/WLAN2400.

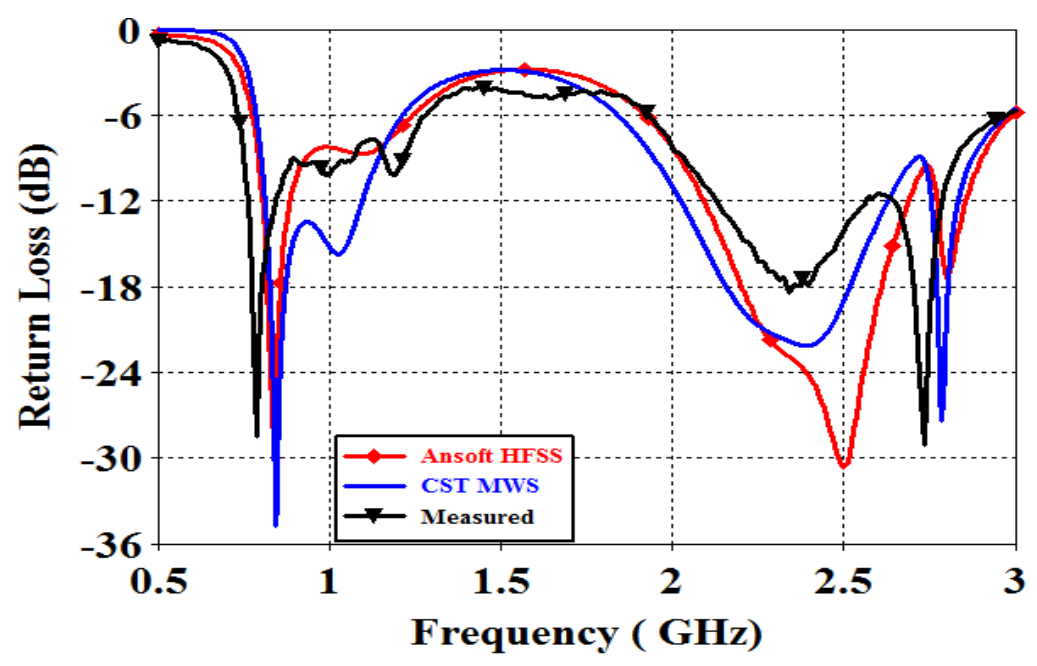

Fig. 7. Measured and simulated return losses for the proposed antenna.

The proposed antenna, without a plastic housing, is presented in Fig.1. The simulated results were also obtained with the presence of the plastic housing of the antenna system. Moreover, to simulate a practical mobile phone casing, a plastic casing with a $1 \mathrm{~mm}$ thick plastic housing, relative permittivity 3.0 and conductivity $0.02 \mathrm{~S} / \mathrm{m}$, is used to enclose the system circuit board with a gap of $1 \mathrm{~mm}$ in distance between the plastic casing and the system circuit board, as seen in Fig.8(a).Noted that the height of the plastic housing is $10 \mathrm{~mm}$ here, which is an attractive height for thin mobile phones, and the proposed planar monopole antenna is at the center of the plastic housing. Fig. 8(b) depicted the simulated return loss against frequency about the two cases (with or without the presence of the plastic housing) for the proposed antenna.

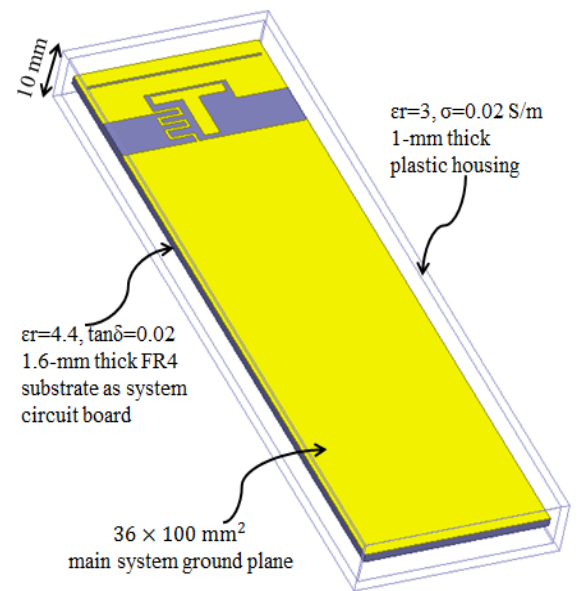

(a)

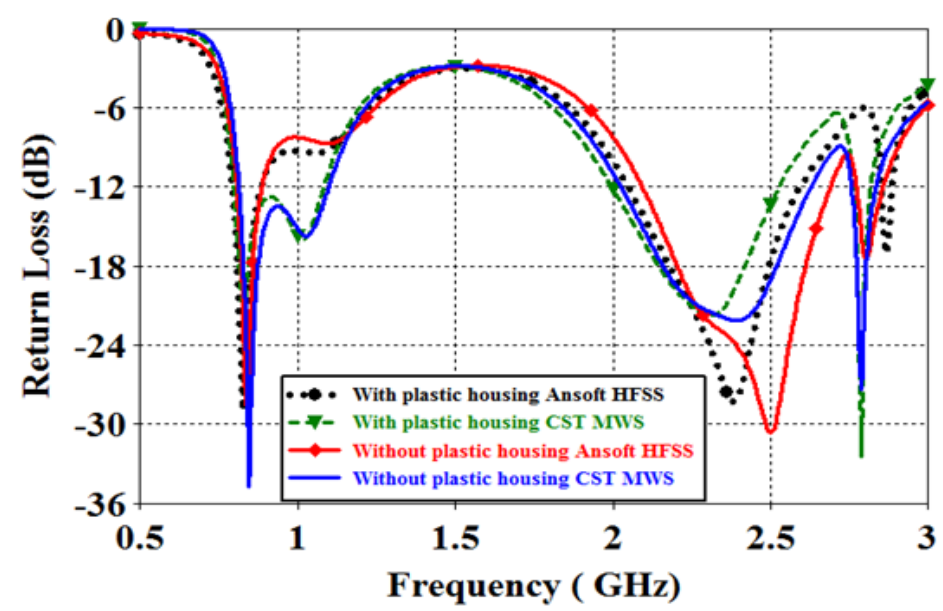

(b)

Fig. 8. (a) Proposed antenna with packaging, (b) simulated return loss against frequency about the two cases (with or without the presence of the plastic housing) for the proposed antenna. 
For more investigations of the antenna performances, Fig.9 illustrates the three-dimensional (3D) gain radiation patterns for the proposed antenna at selected frequencies $(838 \mathrm{MHz}, 900 \mathrm{MHz}$, $1095 \mathrm{MHz}, 2100 \mathrm{MHz}, 2300 \mathrm{MHz}$ and $2450 \mathrm{MHz}$ ). At $838 \mathrm{MHz}, 900 \mathrm{MHz}$ and $1095 \mathrm{MHz}$, a dipolelike radiation patterns with good omnidirectional radiation is obtained, which indicates that stable radiation characteristic is obtained over the antenna's lower band. For higher frequencies at $2100 \mathrm{MHz}, 2300 \mathrm{MHz}$ and $2450 \mathrm{MHz}$ in the second band, more variations in the radiation patterns are seen.

Fig.10 plots the two-dimensional (2D) radiation patterns at typical frequencies including $838 \mathrm{MHz}$, $900 \mathrm{MHz}, 2100 \mathrm{MHz}$ and $2300 \mathrm{MHz}$. Dipole-like radiation patterns at 838MHz and $900 \mathrm{MHz}$ are presented, and omnidirectional radiation in the plane $\left(\varphi=0^{\circ}\right)$ is generally observed. For the radiation patterns in the higher band at $2100 \mathrm{MHz}$ and $2300 \mathrm{MHz}$ in the two planes $\left(\varphi=90^{\circ}\right.$ and $\left.\theta=90^{\circ}\right)$, more variations and nulls in the patterns are seen.

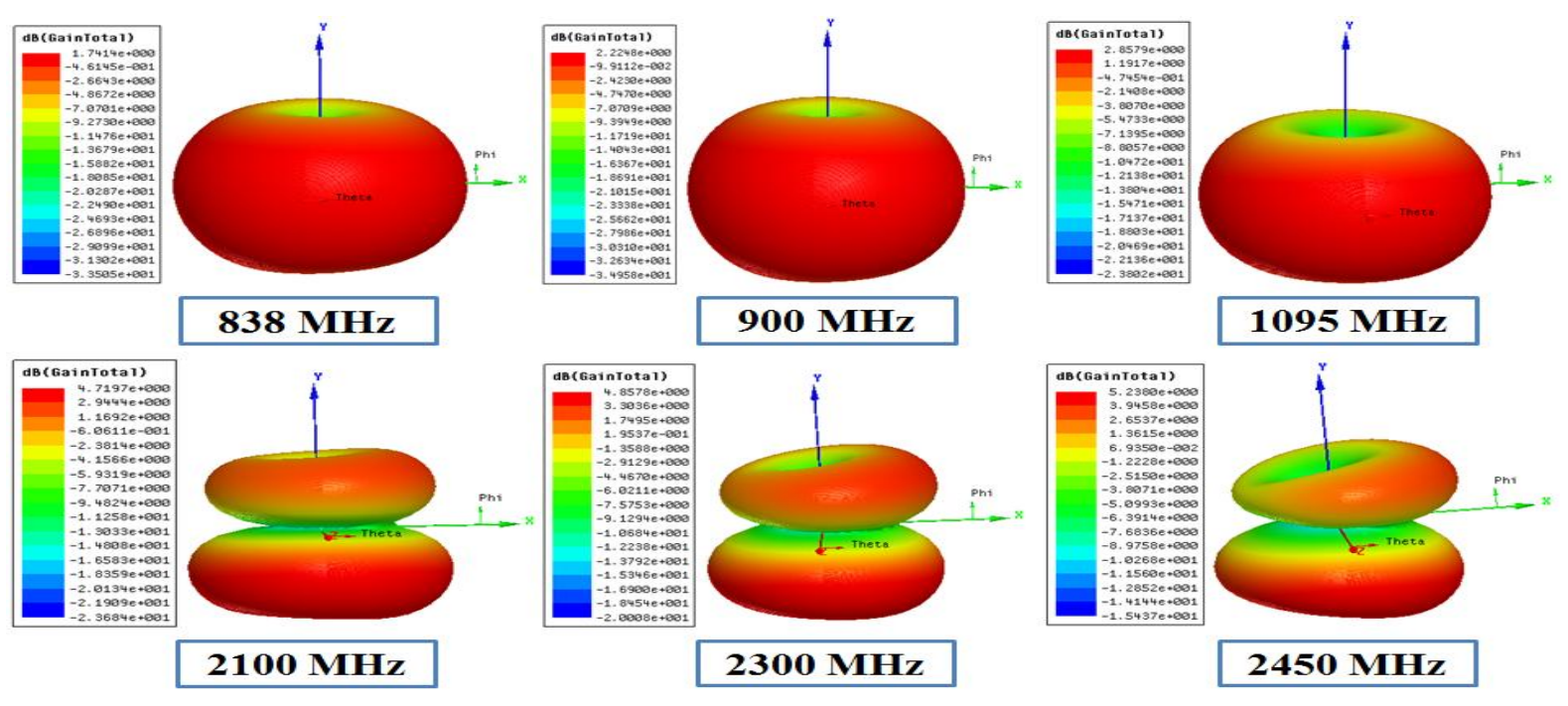

Fig. 9. Gain radiation patterns in 3D at $838 \mathrm{MHz}, 900 \mathrm{MHz}, 1095 \mathrm{MHz}, 2100 \mathrm{MHz}, 2300 \mathrm{MHz}$ and $2450 \mathrm{MHz}$.

\section{ELECTROMAGNETIC DOSIMETRY, POWER ABSORPTION AND SAR}

Electromagnetic dosimetry establishes the relationship between an electromagnetic field distribution in free space and the induced fields inside biological tissues, generally the human body [18].

The Specific Absorption Rate (SAR) is defined as the time derivative of the incremental energy $(d W)$ dissipated in an incremental mass $(d m)$ contained in a volume element $(d V)$ of a given density (

$$
S A R=\frac{d}{d t}\left(\frac{d W}{d m}\right)=\frac{d}{d t}\left(\frac{d W}{\rho d V}\right) \quad(W / k g)
$$

The SAR quantity is related to the internal $E$-field by:

$$
S A R=\frac{\sigma E^{2}}{\rho} \quad(W / k g)
$$




$$
E=\left(\frac{\sigma}{\rho} S A R\right)^{1 / 2}
$$

$$
J=(\sigma \rho S A R)^{1 / 2}
$$

In which, $\rho$ is the mass density in $\mathrm{kg} / \mathrm{m}^{3}, \sigma$ is the electrical conductivity of tissue $(\mathrm{S} / \mathrm{m}), E$ is the root mean square (rms) of electric field strength in volts per meter and $J$ is the current density $\left(\mathrm{A} / \mathrm{m}^{2}\right)$ in tissue.
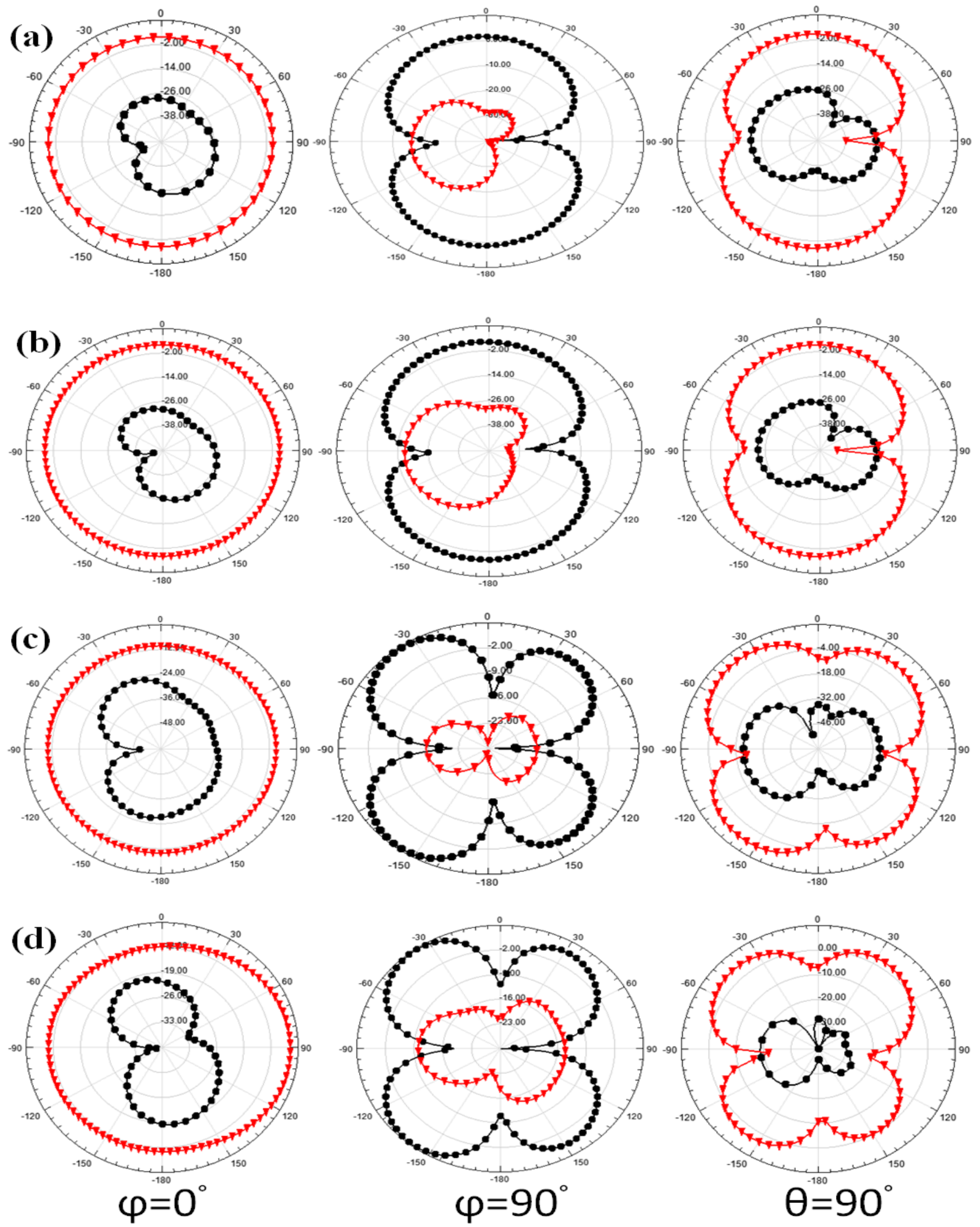

Fig. 10. Radiation patterns in 2D at (a) $838 \mathrm{MHz}$, (b) $900 \mathrm{MHz}$, (c) $2100 \mathrm{MHz}$ and (d) $2300 \mathrm{MHz}$ for the proposed antenna $(\rightarrow \mathrm{dB}$ (GainPhi),,$-\mathrm{dB}($ (GainTheta) ) 


\section{A. Human head model}

In this study, four human head models have been considered. The first model is a homogeneous spherical head with a diameter of $200 \mathrm{~mm}$, consists of a glass shell with $5 \mathrm{~mm}$ thickness and dielectric constant $\varepsilon r=4.6$ and a sphere with $95 \mathrm{~mm}$ radius as the head equivalent materials Fig.11(a). Properties of the head tissue-equivalent dielectric and the glass shell are given in Table I [22]. The second model is a seven-layered spherical head model (diameter $20 \mathrm{~cm}$ ). This model comprises seven types of tissues which are Skin $(2 \mathrm{~mm})$, Fat $(1 \mathrm{~mm})$, Muscle $(4 \mathrm{~mm})$, Skull $(10 \mathrm{~mm})$, Dura (1mm), CSF (Cerebro Spinal Fluid ; $2 \mathrm{~mm}$ ) and Brain $(80 \mathrm{~mm}$ ) [23], Fig.11(b). The dielectric properties of the seven-layer human head model used in the simulations are listed in Table II [24]. The third model is a Specific Anthropomorphic Mannequin (SAM) phantom head provided by CST MWS, which is composed of two layers namely shell and fluid Fig.11(f). The fourth model is a HUGO human head model, also called HUGO. The HUGO head model consists of fifteen types of tissues, namely: Bones, Blood, Cartilages, Eye, Fat Tissue, Glands, Gray Substance, Lens, Marrow, Mucous Membrane, Neuronal Fabric, Nervus Opticus, Skin, Skeleton Muscle, White Substance. The dielectric properties of the HUGO voxel model used in the simulations are obtained from [24]. In this study, the head model is performed at the resolution of $1 \mathrm{~mm}$. Fig.11(g) shows the 3D HUGO human head model and Fig.11(h), Fig.11(i) and Fig.11(j) represent different views of the HUGO voxel model.

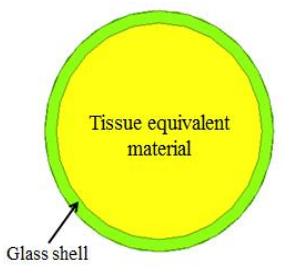

(a)

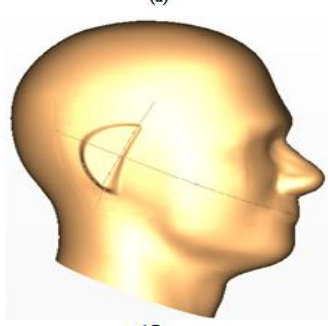

(f)

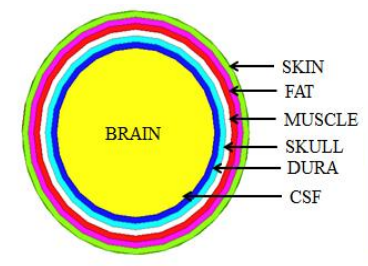

(b)

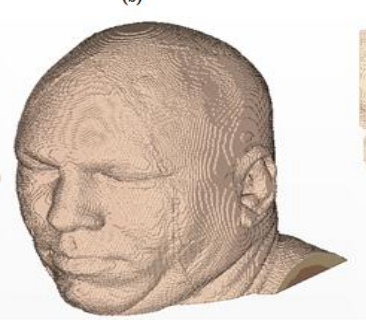

(g)

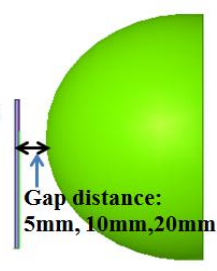

(c)

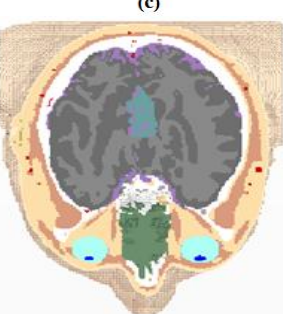

(h)

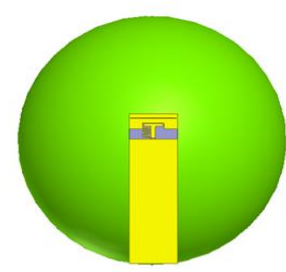

(d)

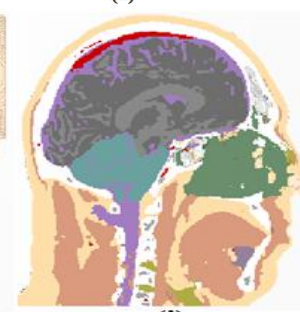

(i)

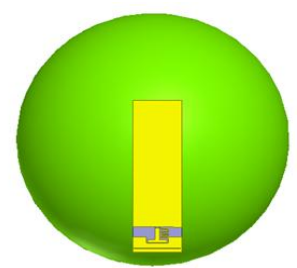

(e)

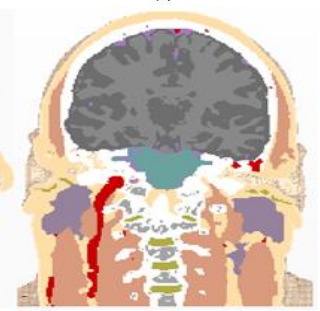

(j)

Fig. 11. Human head model. (a) homogenous head model, (b) head model composed of seven layers ,(c) gap distance, (d) antenna at the top position, (e) antenna at the bottom position.(f) SAM phantom head, (g) 3D HUGO human head at a resolution of $1 \mathrm{~mm}$, (h) top view, (i) side view,(j) front view of the HUGO human head model.

TABLE I. PROPERTIES OF THE TISSUE-EQUIVALENT DIELECTRIC USED FOR THE SPHERICAL HEAD MODEL

\begin{tabular}{|c|c|c|c|c|c|}
\hline \multirow{2}{*}{$\begin{array}{l}\text { Frequency } \\
\quad(\mathrm{MHz})\end{array}$} & \multicolumn{2}{|c|}{ Glass Shell } & \multicolumn{3}{|c|}{ Tissue-equivalent material } \\
\hline & $\begin{array}{c}\text { Relative permittivity } \\
\varepsilon_{\mathrm{r}}\end{array}$ & $\begin{array}{c}\text { Conductivity } \\
\sigma(\mathrm{S} / \mathrm{m})\end{array}$ & $\begin{array}{c}\text { Relative permittivity } \\
\varepsilon_{\mathrm{r}}\end{array}$ & $\begin{array}{c}\text { Conductivity } \\
\sigma(\mathrm{S} / \mathrm{m})\end{array}$ & $\begin{array}{c}\text { Mass density } \\
\rho\left(\mathrm{kg} / \mathrm{m}^{3}\right)\end{array}$ \\
\hline 859 & 4.6 & 0 & 41.5 & 0.90 & 1000 \\
\hline 900 & 4.6 & 0 & 41.5 & 0.97 & 1000 \\
\hline 1900 & 4.6 & 0 & 40.0 & 1.40 & 1000 \\
\hline 2100 & 4.6 & 0 & 39.8 & 1.49 & 1000 \\
\hline 2300 & 4.6 & 0 & 39.5 & 1.67 & 1000 \\
\hline 2400 & 4.6 & 0 & 39.2 & 1.80 & 1000 \\
\hline 2600 & 4.6 & 0 & 39.0 & 1.96 & 1000 \\
\hline
\end{tabular}


TABLE II. DIELECTRIC PROPERTIES OF THE SEVEN-LAYER HUMAN HEAD MODEL

\begin{tabular}{|c|c|c|c|c|c|c|c|c|c|c|c|}
\hline \multirow{2}{*}{$\begin{array}{l}\text { Frequency } \\
\text { (MHz) } \\
\text { Tissue type }\end{array}$} & \multicolumn{2}{|c|}{900} & \multicolumn{2}{|c|}{2100} & \multicolumn{2}{|c|}{2300} & \multicolumn{2}{|c|}{2400} & \multicolumn{2}{|c|}{2500} & \multirow{2}{*}{$\begin{array}{c}\text { Mass } \\
\text { density }\end{array}$} \\
\hline & $\varepsilon_{r}$ & $\sigma(\mathbf{S} / \mathbf{m})$ & $\varepsilon_{r}$ & $\sigma(\mathbf{S} / \mathbf{m})$ & $\varepsilon_{r}$ & $\sigma(\mathbf{S} / \mathbf{m})$ & $\varepsilon_{r}$ & $\sigma(\mathbf{S} / \mathbf{m})$ & $\varepsilon_{r}$ & $\sigma(\mathbf{S} / \mathbf{m})$ & \\
\hline SKIN & 43.8 & 0.86 & 38.43 & 1.30 & 38.18 & 1.40 & 38.06 & 1.44 & 37.95 & 1.49 & 1100 \\
\hline FAT & 11.3 & 0.11 & 5.32 & 0.09 & 5.30 & 0.10 & 5.28 & 0.10 & 5.27 & 0.11 & 1100 \\
\hline MUSCLE & 55.9 & 0.97 & 54.04 & 1.57 & 53.77 & 1.70 & 53.64 & 1.77 & 53.51 & 1.85 & 1040 \\
\hline SKULL & 20.8 & 0.34 & 15.28 & 0.50 & 15.10 & 0.56 & 15.01 & 0.59 & 14.92 & 0.61 & 1850 \\
\hline DURA & 44.4 & 0.96 & 42.49 & 1.47 & 42.23 & 1.58 & 42.10 & 1.64 & 41.97 & 1.70 & 1030 \\
\hline CSF & 68.6 & 2.41 & 66.76 & 3.15 & 66.47 & 3.32 & 66.32 & 3.41 & 66.17 & 3.50 & 1030 \\
\hline BRAIN & 45.8 & 0.77 & 43.05 & 1.31 & 42.75 & 1.42 & 42.61 & 1.48 & 42.47 & 1.54 & 1030 \\
\hline
\end{tabular}

\section{SAR ANALYSIS OF THE PROPOSED ANTENNA}

In this paper, the SAR values of the planar monopole antenna with a T-shaped coupling feed and an inductive shorting strip for LTE/WWAN/WLAN in the internal mobile phone are studied using FEM (Finite Element Method) based Ansoft's HFSS and FIT (Finite Integration Technique) based CST MWS. In this research work, the input power for the SAR calculations is $24 \mathrm{dBm}$ or $250 \mathrm{~mW}$ for the lower band (734-1280 MHz) and 21dBm or $125 \mathrm{~mW}$ for the upper band (1934-3000 MHz). Notice that, the local and average SARs levels are calculated within the spherical human head model, along the SAR line and normalized to the maximum distance $60 \mathrm{~mm}$.

\section{A. SAR distribution in homogenous head model}

The effects of the operating frequency and the gap distance between the mobile phone antenna and the homogenous head model on SAR distributions are discussed in this section. Fig.12 shows the variation levels of the local SAR and the SAR averaging over a mass of 1 gram, at various gap distances ( $5 \mathrm{~mm}, 10 \mathrm{~mm}$ and $20 \mathrm{~mm}$ ) between the proposed antenna and the homogenous sphere head model, at the selective operating frequencies of $900 \mathrm{MHz}, 2100 \mathrm{MHz}$ and $2300 \mathrm{MHz}$. Noted that the antenna is positioned at the bottom of the mobile phone. It can be seen that the levels of the local and average SAR decreases when the gap distance increases, also with penetration into the homogenous head, the average SAR values for all frequencies decrease rapidly.

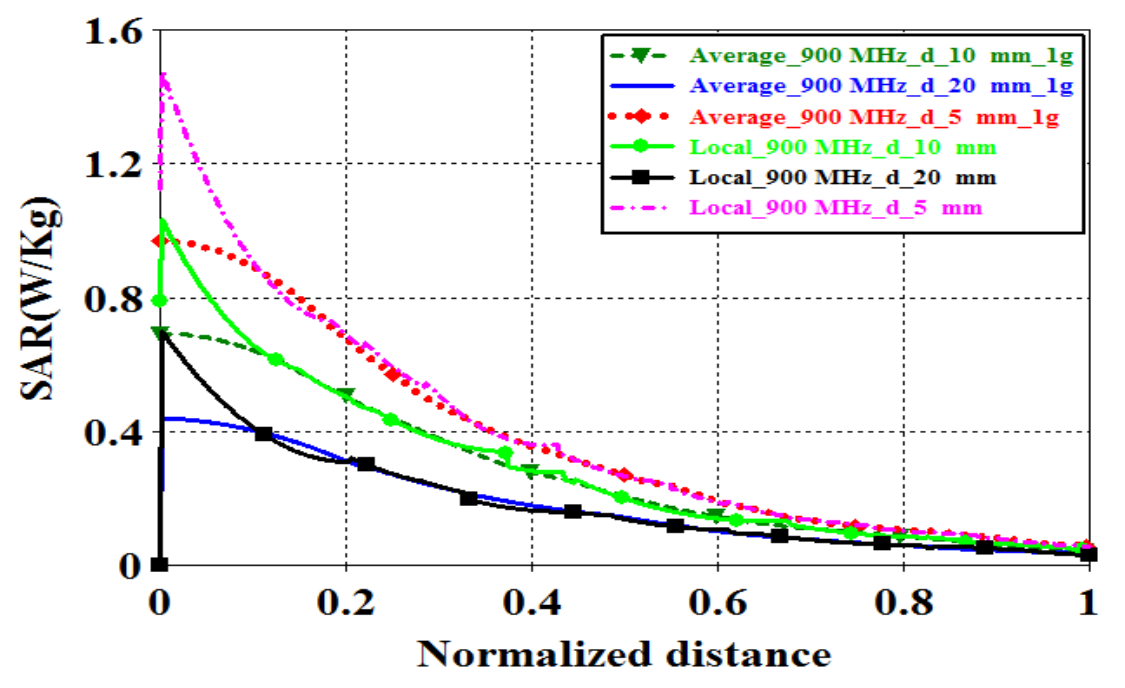

Brazilian Microwave and Optoelectronics Society-SBMO Brazilian Society of Electromagnetism-SBMag 

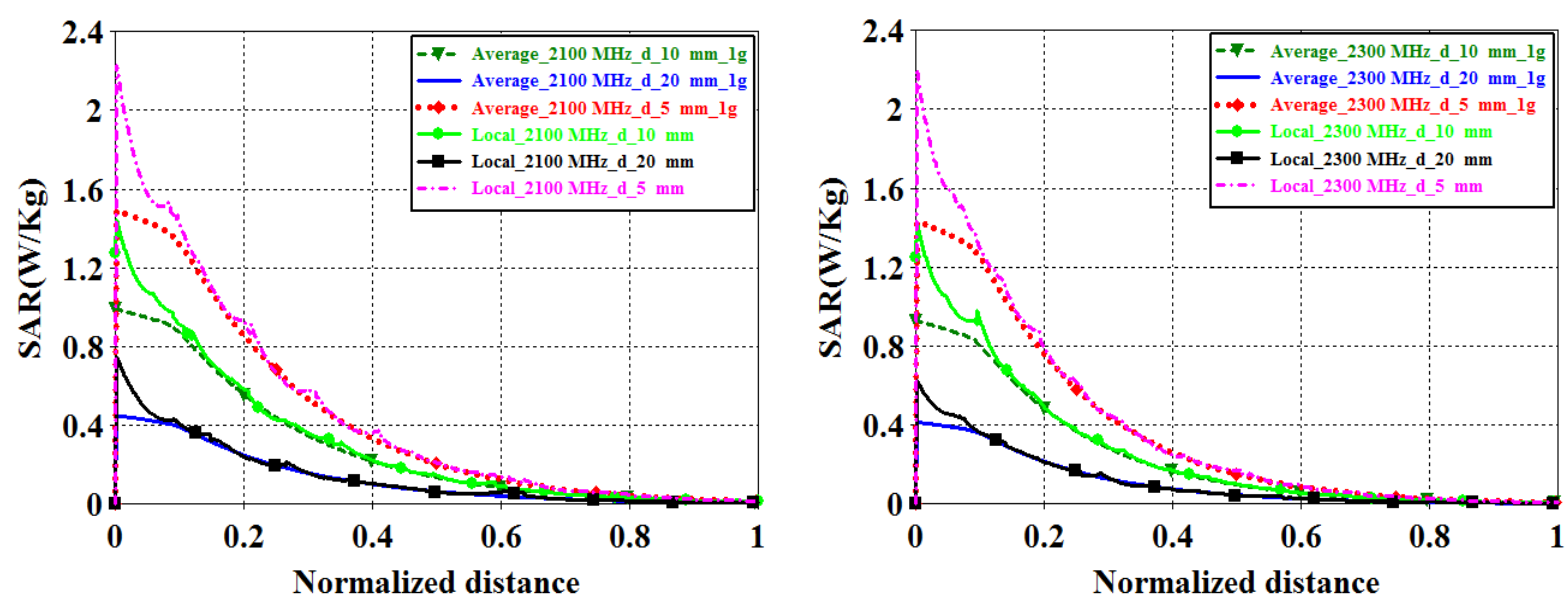

Fig. 12. Local SAR and Average SAR variation in $1 \mathrm{~g}$ head tissues for homogenous head model, at different frequencies, at various gap distances.

Fig.13(a) and Fig.13(b) show the simulated 3D $1 \mathrm{~g}$ SAR distributions (W/kg) and 2D $10 \mathrm{~g} \mathrm{SAR}$ respectively, within the tissue-equivalent material, at the frequencies of $900 \mathrm{MHz}, 2100 \mathrm{MHz}$ and $2300 \mathrm{MHz}$, with the gap distance fixed to $20 \mathrm{~mm}$, obtained using Ansoft HFSS and CST MWS.
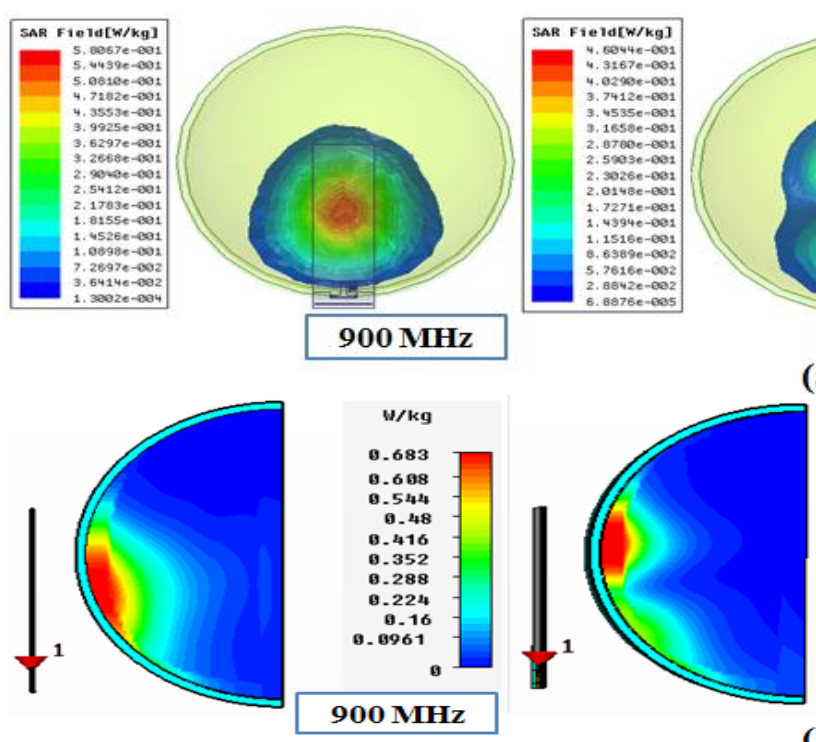
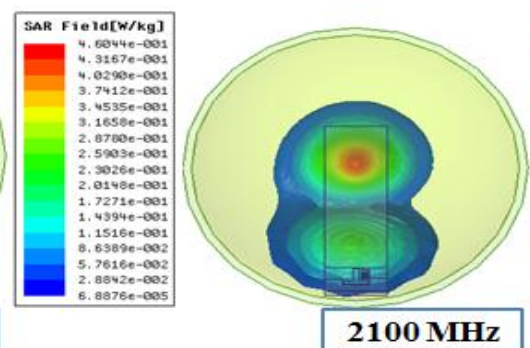

(a)
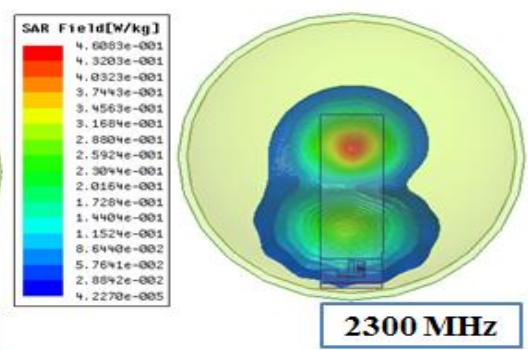

$2300 \mathrm{MHz}$
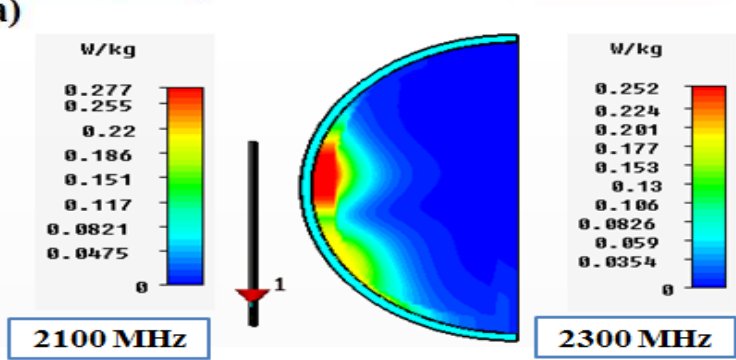

(b)

Fig. 13. Simulated (a) 3D $1 \mathrm{~g}$ SAR and (b) 2D $10 \mathrm{~g} \mathrm{SAR}$ distributions (W/kg) inside the tissue-equivalent material at the frequencies of $900 \mathrm{MHz}, 2100 \mathrm{MHz}$ and $2300 \mathrm{MHz}$, with $20 \mathrm{~mm}$ gap distance using Ansoft HFSS and CST MWS.

TABLE III. E-FIELD STRENGTH DISTRIBUTIONS (VOLT/METER), ONE GRAM SAR AND TEN GRAMS SAR DiSTRIBUTIONS (W/KG), INSIDE THE TISSUE-EQUIVALENT MATERIAL, FOR THE ANTENNA PLACED AT THE BOTTOM OF THE MOBILE PHONE, WITH 20 MILLIMETER GAP DISTANCE

\begin{tabular}{ccccc}
\hline Software & \multicolumn{2}{c}{ Ansoft HFSS } & \multicolumn{2}{c}{ CST MWS } \\
\hline $\begin{array}{c}\text { Frequency } \\
\text { (MHz) }\end{array}$ & $\begin{array}{c}\text { E-field strength } \\
(\mathbf{V} / \mathbf{m})\end{array}$ & $\mathbf{1 ~ g ~ S A R ~ ( W / k g ) ~}$ & $\mathbf{1 ~ g ~ S A R ~ ( W / k g ) ~}$ & $\mathbf{1 0}$ g SAR (W/kg) \\
\hline $\mathbf{9 0 0}$ & 30.1 & 0.580 & 0.905 & 0.683 \\
$\mathbf{1 9 0 0}$ & $*$ & $*$ & 0.557 & 0.349 \\
$\mathbf{2 1 0 0}$ & 24.6 & 0.460 & 0.455 & 0.277 \\
$\mathbf{2 3 0 0}$ & 22.8 & 0.460 & 0.435 & 0.252 \\
$\mathbf{2 4 0 0}$ & 24.2 & 0.477 & 0.448 & 0.252 \\
$\mathbf{2 6 0 0}$ & $*$ & $*$ & 0.452 & 0.247 \\
\hline
\end{tabular}


Table III gives a summary of the E-field intensity (V/m), for the averaged $1 \mathrm{~g} \mathrm{SAR}(\mathrm{W} / \mathrm{kg})$ and $10 \mathrm{~g}$ SAR (W/kg), within the tissue-equivalent material, for the selected operating frequencies, when the antenna is placed at the bottom of the mobile phone. The results indicate that the planar monopole antenna complies with the SAR limits recommended by the FCC, which is $1.6 \mathrm{~W} / \mathrm{kg}$ averaged over $1 \mathrm{~g}$ of tissue and the ICNIRP, or $2 \mathrm{~W} / \mathrm{kg}$ for the $10 \mathrm{~g}$ head tissue.

B. SAR distribution in the seven-layer human head model

The SAR levels, for the spherical seven layer human head model, were also investigated using the Ansoft HFSS. Two cases of the antenna placed at the top and bottom positions are presented in Fig.11(d) and Fig.11(e) respectively. The effect of the gap distance between the antenna and the spherical seven layer head model on SAR distributions at selective frequencies is systematically analyzed.
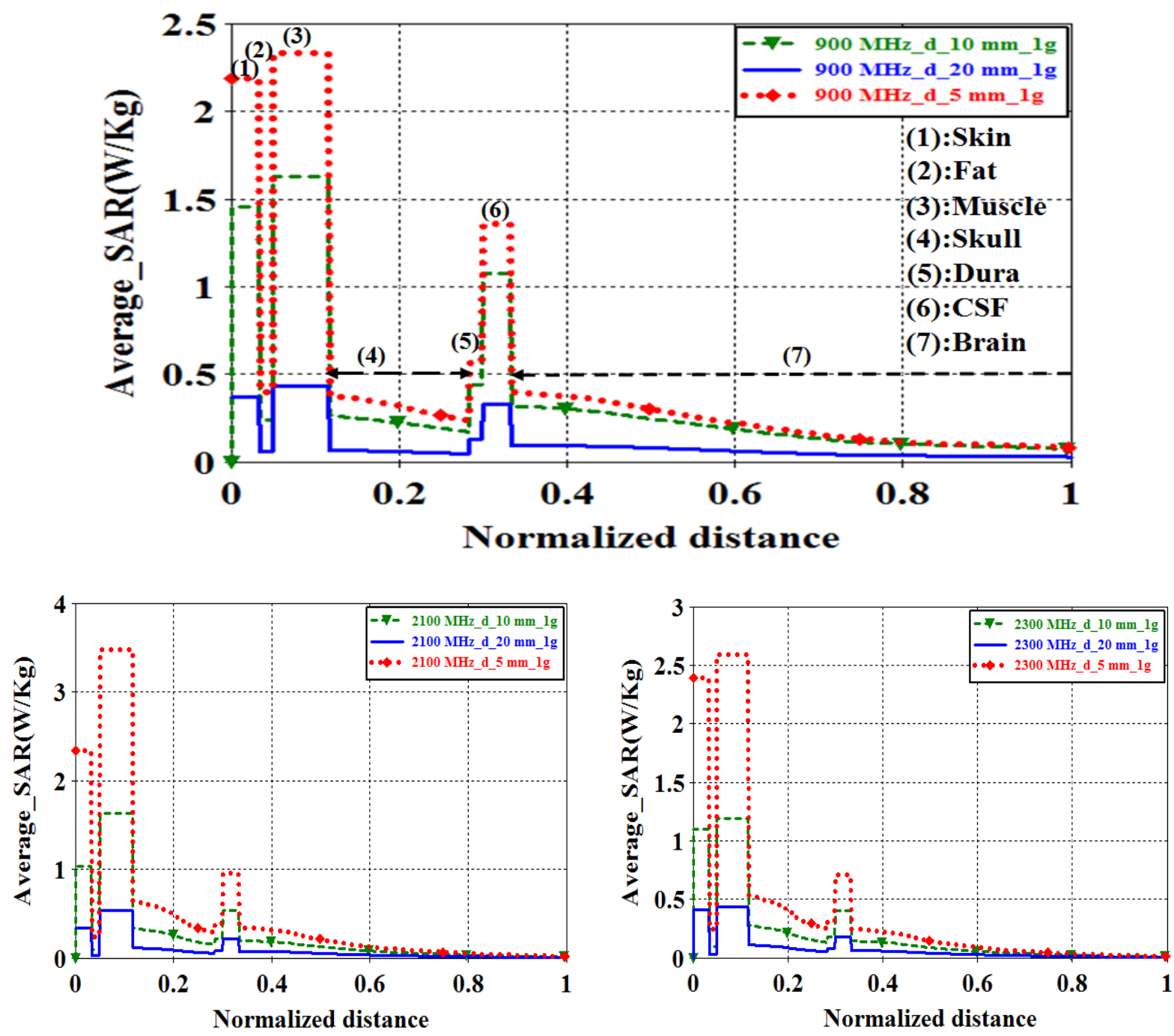

Fig. 14. Averaged $1 \mathrm{~g} \mathrm{SAR}(\mathrm{W} / \mathrm{kg}$ ) Distribution within the spherical seven layer head model, at various gap distances, at different frequencies, the antenna is placed at the top position of the mobile phone. 
The obtained results of the average $1 \mathrm{~g} \mathrm{SAR}$ distribution inside the spherical seven layer human head model, at various gap distances $(5 \mathrm{~mm}, 10 \mathrm{~mm}$ and $20 \mathrm{~mm}$ ), and different frequencies $(900 \mathrm{MHz}$, $2100 \mathrm{MHz}$ and $2300 \mathrm{MHz}$ ) are illustrated in Fig.14. In this case the antenna is mounted at the top of the mobile phone of the user's head. It can be seen that the peaks appear in the skin, muscle and CSF
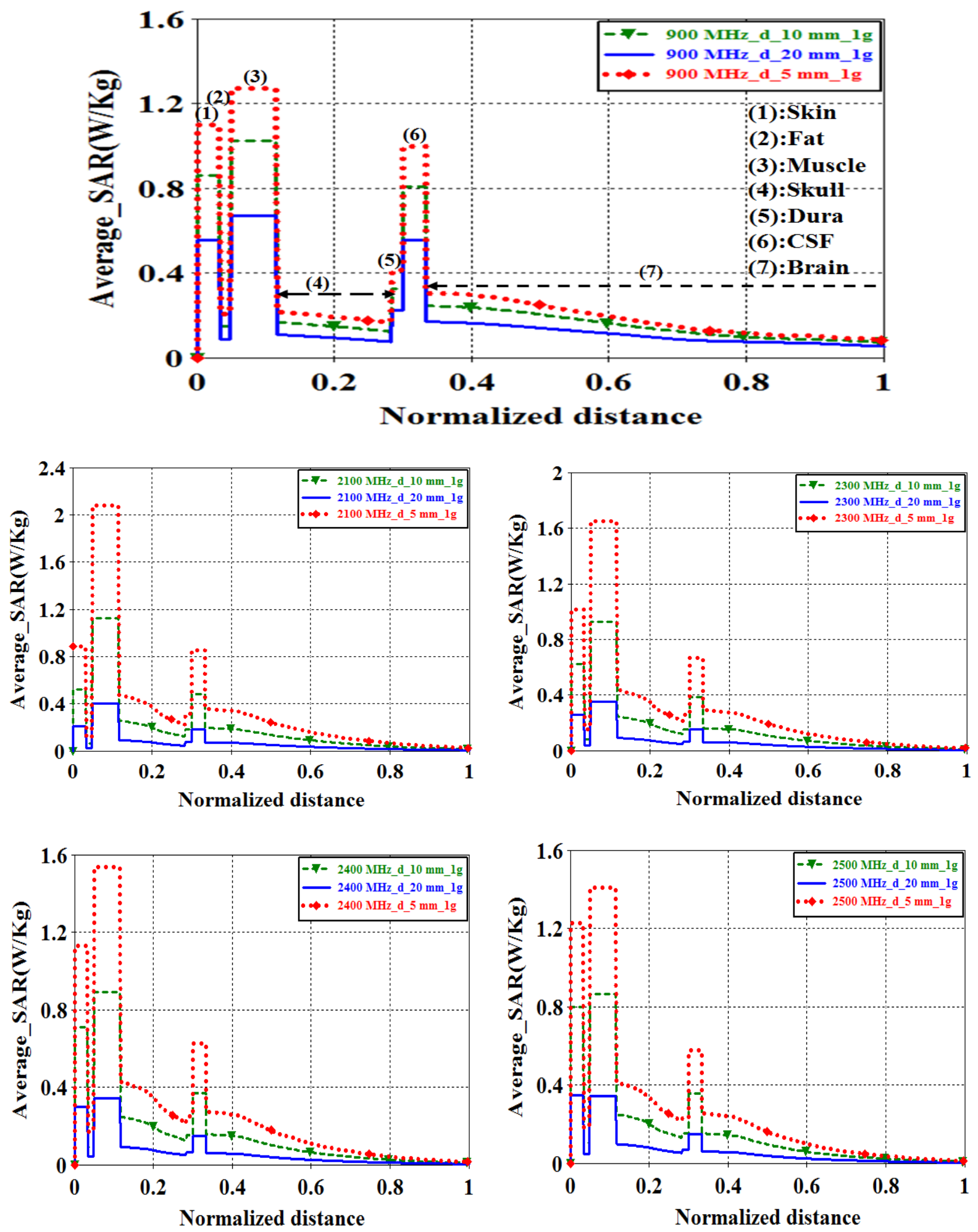

Fig. 15. Averaged $1 \mathrm{~g}$ SAR Distribution within the spherical seven layer head model, at various gap distances, at different frequencies, the antenna is placed at the bottom position of the mobile phone. 
layers with high values of SAR, because these tissues have relatively high dielectric proprieties (conductivity and relative permittivity) value compared to the fat, skull, dura and brain. When the proposed antenna is very close to the seven layer head model $(5 \mathrm{~mm})$, the SAR levels exceed the FCC standard, in skin and muscle layers at the three frequencies of interest, but when the gap distance is fixed to $10 \mathrm{~mm}$, only the SAR value in muscle tissue exceed the standard SAR limit which is $1.6 \mathrm{~W} / \mathrm{kg}$, at the frequencies of $900 \mathrm{MHz}$ and $2100 \mathrm{MHz}$. Also it was found that, for all frequencies, the SAR levels in all tissues decreased when the gap distance increased from $5 \mathrm{~mm}$ to $20 \mathrm{~mm}$.

Fig.15 shows the comparison of the average $1 \mathrm{~g}$ SAR distribution inside the spherical seven layer human head model, at various gap distances, at different frequencies of $900 \mathrm{MHz}, 2100 \mathrm{MHz}$, $2300 \mathrm{MHz}, 2400 \mathrm{MHz}$ and $2500 \mathrm{MHz}$. Notice that the antenna is placed at the bottom of the mobile phone as shown in Fig.11 (e). From the obtained results illustrated in Fig .15, when the gap distance is fixed to $5 \mathrm{~mm}$, the SAR values in muscle tissue exceed the standard limit, only at the selected frequencies of $2100 \mathrm{MHz}$ and $2300 \mathrm{MHz}$. On the other hand, for the two gap distances $\mathrm{d}=10 \mathrm{~mm}$ and $\mathrm{d}=20 \mathrm{~mm}$, the SAR levels in all tissues are all below the standard limit, for all selected frequencies. In addition, it can be observed that increasing the gap distance will lead to rapid decrease in the levels of the SAR.

Based on the simulation results, there is a certain influence of the gap distance between the antenna and human head on SAR reduction, as can be observed in Fig.14 and Fig.15. If the distance between the antenna and the spherical seven layer head model is increased from $5 \mathrm{~mm}$ to $20 \mathrm{~mm}$, then the SAR levels also decreases. In addition, the SAR levels differ from one tissue to another because different tissues are located differently with respect to the monopole antenna and electric parameters (conductivities, relative permittivity) vary among the tissues. It can be seen from the simulated results that the SAR values at the bottom position are lower than at the top position. It seems that placing the antenna at the bottom edge is more promising for practical mobile phone applications.

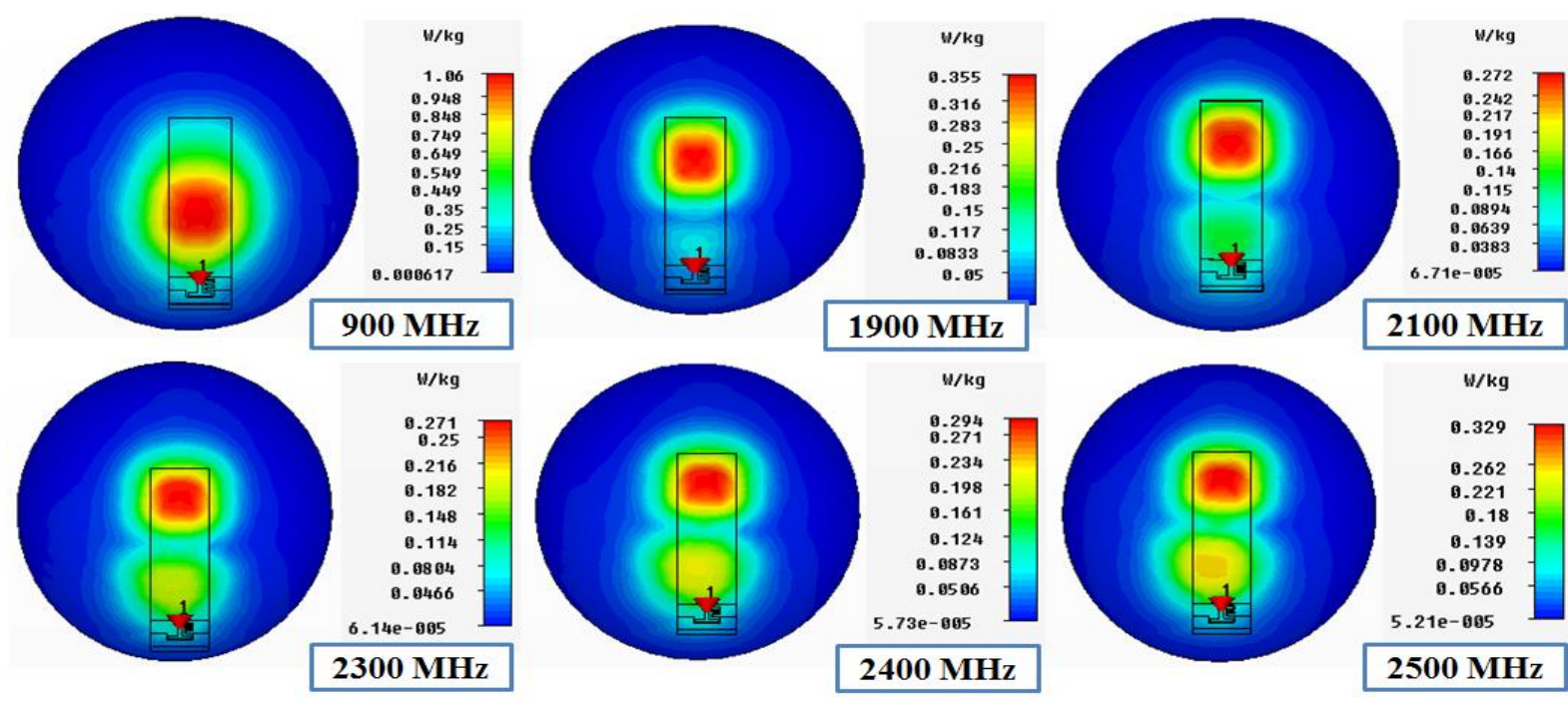

Fig. 16. Simulated 3D $1 \mathrm{~g}$ SAR distributions (W/kg), inside the spherical seven layer head model, at the frequencies of $900 \mathrm{MHz}, 1900 \mathrm{MHz}, 2100 \mathrm{MHz}, 2300 \mathrm{MHz}, 2400 \mathrm{MHz}$ and $2500 \mathrm{MHz}$, with $20 \mathrm{~mm}$ gap distance using CST MWS. 
The simulated 3D $1 \mathrm{~g}$ SAR distributions (W/kg), and 2D $10 \mathrm{~g} \mathrm{SAR}(\mathrm{W} / \mathrm{kg})$, inside the spherical seven layer human head model are presented in Fig.16 and Fig.17 respectively, at the frequencies of $900 \mathrm{MHz}, 1900 \mathrm{MHz}, 2100 \mathrm{MHz}, 2300 \mathrm{MHz}, 2400 \mathrm{MHz}$ and $2500 \mathrm{MHz}$, with the gap distance fixed to $20 \mathrm{~mm}$ obtained using CST MWS. Notice that the mobile phone in the study has the proposed antenna positioned at the bottom of the system circuit board.

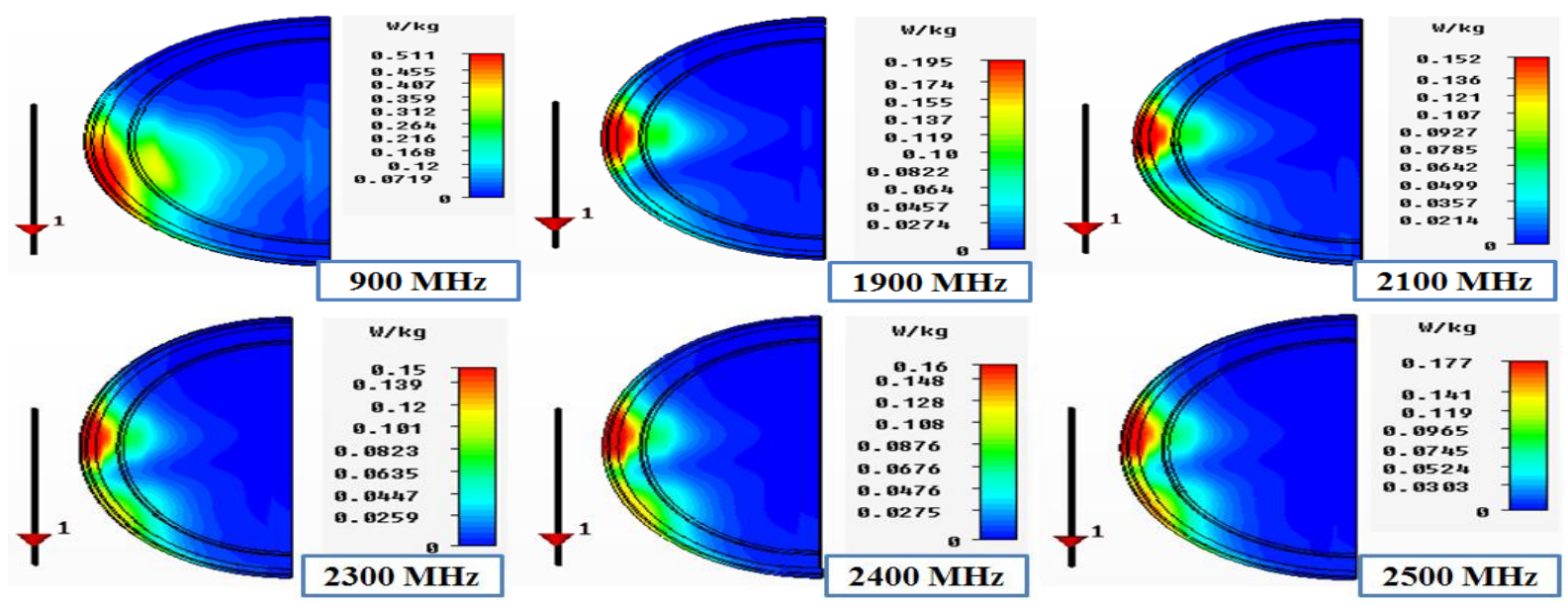

Fig. 17. Simulated 2D $10 \mathrm{~g}$ SAR distributions (W/kg), inside the spherical seven layer head model, at the frequencies of $900 \mathrm{MHz}, 1900 \mathrm{MHz}, 2100 \mathrm{MHz}, 2300 \mathrm{MHz}, 2400 \mathrm{MHz}$ and $2500 \mathrm{MHz}$, with $20 \mathrm{~mm}$ gap distance using CST MWS.

The SAR calculations for $1 \mathrm{~g}$ and $10 \mathrm{~g}$ head tissues, obtained using the CST MWS, are listed in Table IV. It is found that for all aforementioned operating frequencies, the SAR in $1 \mathrm{~g}$ head tissue was always higher than the SAR in $10 \mathrm{~g}$ head tissues. Moreover, the SAR values obtained from this study are below the SAR limit of $1.6 \mathrm{~W} / \mathrm{kg}$ for the $1 \mathrm{~g}$ head tissue (according to the FCC standard) and $2.0 \mathrm{~W} / \mathrm{kg}$ for the $10 \mathrm{~g}$ head tissue (according to the ICNIRP standard).

TABLE IV. SIMULATED SAR IN ONE GRAM AND TEN GRAMS HEAD TISSUES, OBTAINED FROM CST MWS FOR THE ANTENNA PLACED AT THE BOTTOM OF THE MOBILE PHONE, WITH THE PRESENCE OF THE SPHERICAL SEVEN LAYER HEAD MODEL, WITH 20 MILLIMETER GAP DISTANCE

\begin{tabular}{cccc}
\hline Frequency $(\mathbf{M H z})$ & Input power $(\mathbf{d B m})$ & $\mathbf{1} \mathbf{g} \mathbf{S A R}(\mathbf{W} / \mathbf{k g})$ & $\mathbf{1 0} \mathbf{g} \mathbf{S A R}(\mathbf{W} / \mathbf{k g})$ \\
\hline $\mathbf{9 0 0}$ & 24 & 1.06 & 0.511 \\
$\mathbf{1 9 0 0}$ & 21 & 0.355 & 0.195 \\
$\mathbf{2 1 0 0}$ & 21 & 0.272 & 0.152 \\
$\mathbf{2 3 0 0}$ & 21 & 0.271 & 0.15 \\
$\mathbf{2 4 0 0}$ & 21 & 0.294 & 0.16 \\
$\mathbf{2 5 0 0}$ & 21 & 0.329 & 0.177 \\
\hline
\end{tabular}

\section{C. $\quad$ SAR distribution in the Specific Anthropomorphic Mannequin (SAM) phantom head model}

The Specific Anthropomorphic Mannequin (SAM) phantom head model provided by CST Microwave Studio, was used after the SAR validation using homogenous spherical head model and spherical seven layer head model. The simulated average SAR over $1 \mathrm{~g}$ and $10 \mathrm{~g}$, for the SAM phantom head model is also studied in this section. In this case, the antenna is placed at the bottom position of the mobile phone with the presence of the SAM head model. The input power for the SAR 
calculations is $24 \mathrm{dBm}$ for the $859 \mathrm{MHz}$ and $925 \mathrm{MHz}$, and $21 \mathrm{dBm}$ for the $1920 \mathrm{MHz}, 2045 \mathrm{MHz}$, $2300 \mathrm{MHz}, 2450 \mathrm{MHz}$ and $2600 \mathrm{MHz}$.

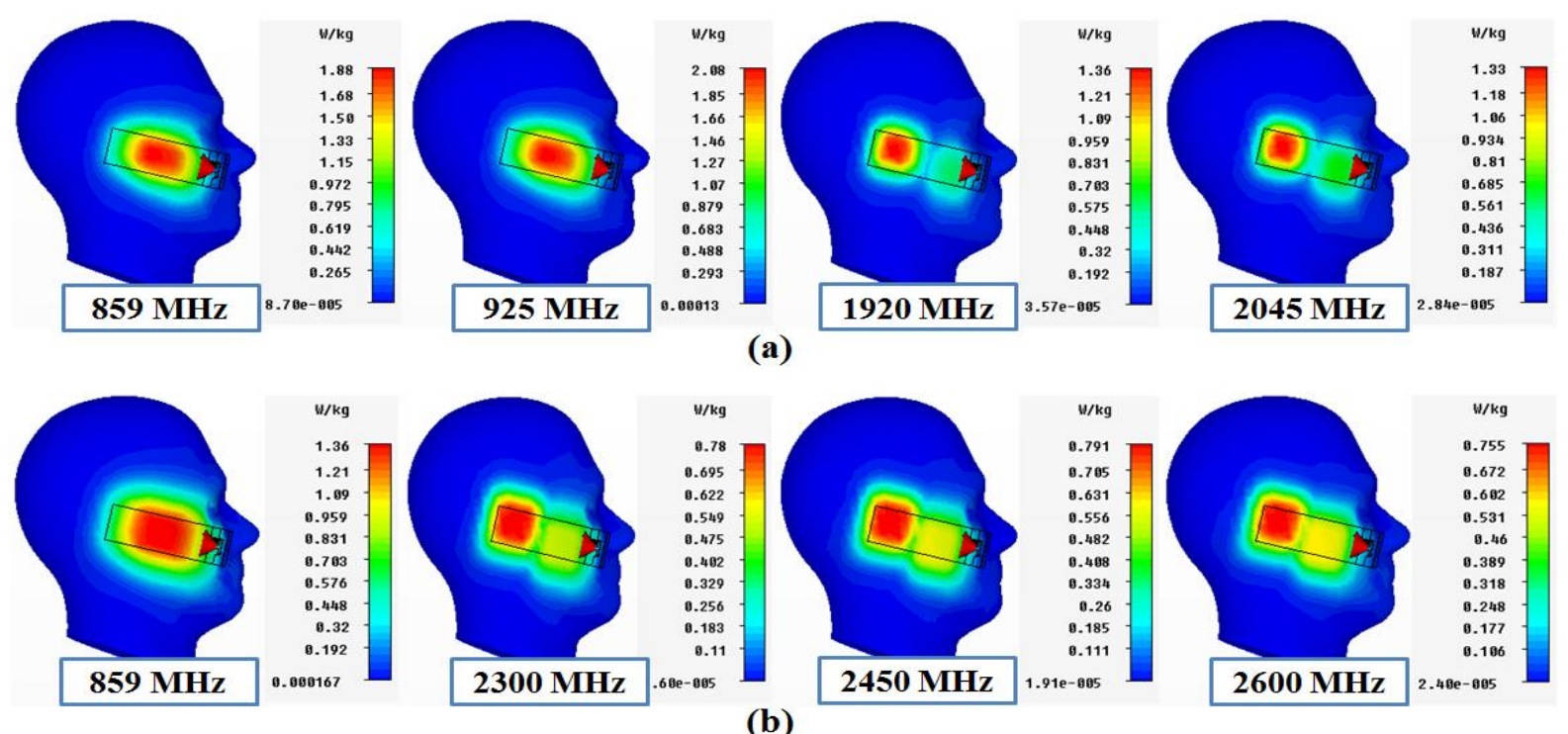

Fig. 18. Simulated (a) 3D $1 \mathrm{~g} \mathrm{SAR}$ distributions (W/kg), at the frequencies of $859 \mathrm{MHz}, 925 \mathrm{MHz}, 1920 \mathrm{MHz}$ and $2045 \mathrm{MHz}$, and (b) $10 \mathrm{~g} \mathrm{SAR}$ distributions (W/kg), at the $859 \mathrm{MHz}, 2300 \mathrm{MHz}, 2450 \mathrm{MHz}$ and $2600 \mathrm{MHz}$, inside the SAM phantom head, with $5 \mathrm{~mm}$ gap distance .

Fig.18(a) and Fig.18(b) demonstrate the simulated 3D 1 g SAR distributions (W/kg), at the frequencies of $859 \mathrm{MHz}, 925 \mathrm{MHz}, 1920 \mathrm{MHz}$ and $2045 \mathrm{MHz}$, and $10 \mathrm{~g}$ SAR distributions (W/kg), at the $859 \mathrm{MHz}, 2300 \mathrm{MHz}, 2450 \mathrm{MHz}$ and $2600 \mathrm{MHz}$, inside the SAM phantom head, respectively, with the gap distance is fixed to $5 \mathrm{~mm}$ obtained using CST MWS. The obtained SAR results, calculated over $1 \mathrm{~g}$ and $10 \mathrm{~g}$ head tissues, for $\mathrm{d}=5 \mathrm{~mm}$ and $\mathrm{d}=20 \mathrm{~mm}$ are summarized in Table $\mathrm{V}$. When the gap $\mathrm{d}=5 \mathrm{~mm}$, it is noticed that the SAR values obtained by using a SAM phantom head, are all below the SAR limit of $2.0 \mathrm{~W} / \mathrm{kg}$ for the $10 \mathrm{~g}$ head tissue, and $1.6 \mathrm{~W} / \mathrm{kg}$ in a $1 \mathrm{~g}$ averaging mass, except for the $859 \mathrm{MHz}$ and $925 \mathrm{MHz}$ which the SAR values exceed $1.6 \mathrm{~W} / \mathrm{kg}$.

TABLE V. SIMULATED ONE GRAM SAR DISTRIBUTIONS (W/KG) AND TEN GRAMS SAR (W/KG), INSIDE THE SAM PHANTOM HEAD, FOR THE ANTENNA PLACED AT THE BOTTOM OF THE MOBILE PHONE, WITH 5 MILLIMETER AND 20 MILLIMETER GAP DISTANCE

\begin{tabular}{|c|c|c|c|c|c|c|c|c|}
\hline & Frequency (MHz) & 859 & 925 & 1920 & 2045 & 2300 & 2450 & 2600 \\
\hline Distance & Input power (dBm) & 24 & 24 & 21 & 21 & 21 & 21 & 21 \\
\hline $\mathrm{d}=5 \mathrm{~mm}$ & 1 g SAR (W/kg) & 1.88 & 2.08 & 1.36 & 1.33 & 1.42 & 1.50 & 1.48 \\
\hline $\mathrm{d}=5 \mathrm{~mm}$ & 10 g SAR (W/kg) & 1.36 & 1.48 & 0.829 & 0.787 & 0.78 & 0.791 & 0.755 \\
\hline $\mathrm{d}=20 \mathrm{~mm}$ & 1 g SAR (W/kg) & 0.873 & 0.915 & 0.483 & 0.444 & 0.429 & 0.450 & 0.466 \\
\hline $\mathrm{d}=20 \mathrm{~mm}$ & $10 \mathrm{~g} \mathrm{SAR}(\mathrm{W} / \mathrm{kg})$ & 0.666 & 0.69 & 0.314 & 0.283 & 0.264 & 0.268 & 0.267 \\
\hline
\end{tabular}

\section{SAR distribution in the HUGO human head model}

In this section, we evaluate the SAR in the anatomically based head model, called HUGO human head model, by using FIT (Finite Integration Technique) based CST MWS. The SAR distributions within the HUGO voxel model are calculated for three gap distances $5 \mathrm{~mm}, 10 \mathrm{~mm}$ and $20 \mathrm{~mm}$, for the selected operating frequencies, for the proposed antenna placed at the bottom position of the mobile phone. 
Fig.19(a) and Fig.19(b) depicted the simulated 3D 10 g SAR distributions (W/kg) and the 2D top cut plane view of the $1 \mathrm{~g}$ SAR distributions (W/kg), inside the HUGO head model, respectively, at the frequencies of $859 \mathrm{MHz}, 925 \mathrm{MHz}, 1920 \mathrm{MHz}$ and $2450 \mathrm{MHz}$, with the gap distance is fixed to $5 \mathrm{~mm}$.
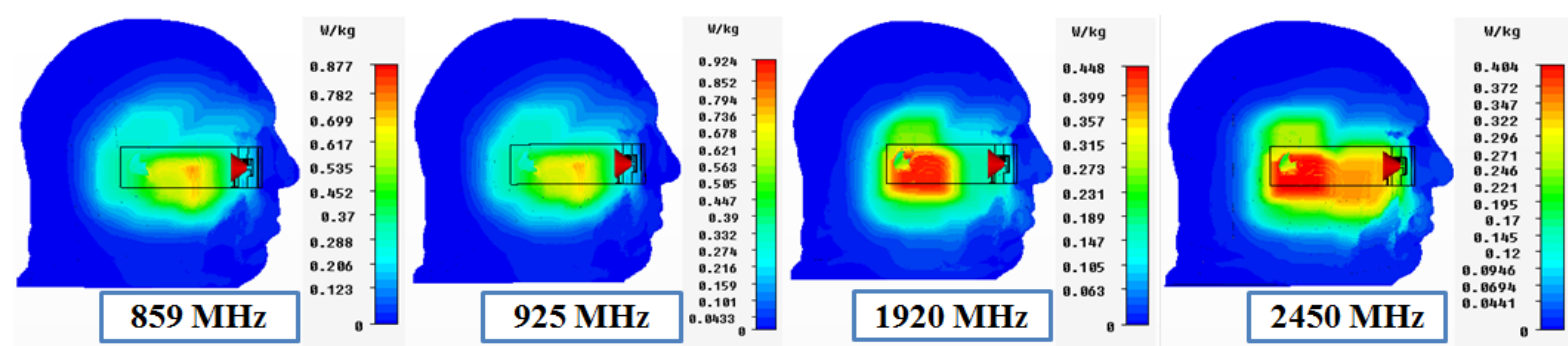

(a)
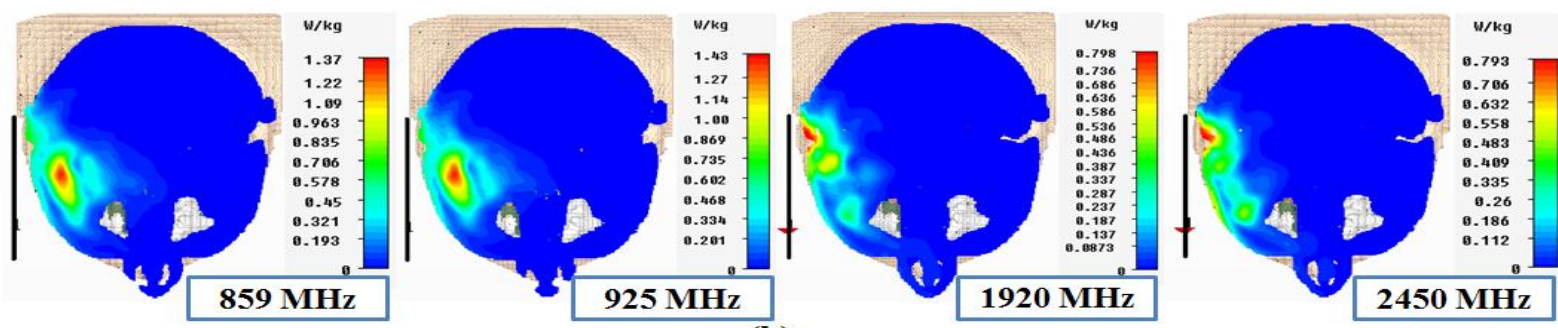

(b)

Fig. 19. Simulated (a) 3D $10 \mathrm{~g}$ SAR distributions (W/kg) and (b) $2 \mathrm{D} 1 \mathrm{~g}$ SAR distributions (W/kg) inside the HUGO human head model,respectively, at the frequencies of $859 \mathrm{MHz}, 925 \mathrm{MHz}, 1920 \mathrm{MHz}$ and $2450 \mathrm{MHz}$, with $5 \mathrm{~mm}$ gap distance.

Table VI illustrates the simulated peak $1 \mathrm{~g}$ and $10 \mathrm{~g}$ SARs, within the HUGO human head model, for the selected operating frequencies. From the obtained results, it is clearly seen that the averaged $1 \mathrm{~g}$ and $10 \mathrm{~g}$ SARs results, are all well bellow the SAR limits of $1.6 \mathrm{~W} / \mathrm{kg}$ and $2.0 \mathrm{~W} / \mathrm{kg}$ standards respectively, at all frequencies, for the three gap distances. When the gap distance is fixed to $5 \mathrm{~mm}$, the obtained maximum peak average SAR over $1 \mathrm{~g}$ and $10 \mathrm{~g}$ are $1.43 \mathrm{~W} / \mathrm{kg}$ and $0.924 \mathrm{~W} / \mathrm{kg}$, respectively at $925 \mathrm{MHz}$, whereas the obtained minimum peak average SAR over $1 \mathrm{~g}$ and $10 \mathrm{~g}$ are $0.793 \mathrm{~W} / \mathrm{kg}$ and $0.404 \mathrm{~W} / \mathrm{kg}$, respectively at $2450 \mathrm{MHz}$. The obtained results indicate that the proposed antenna is competitive for practical mobile phone applications.

TABLE VI. SIMULATED ONE GRAM SAR DISTRIBUTIONS (W/KG) AND TEN GRAMS SAR (W/KG), INSIDE THE HUGO HEAD MODEL, FOR THE ANTENNA PLACED AT THE BOTTOM OF THE MOBILE PHONE, WITH 5,10 AND 20 MILLIMETERS GAP DISTANCE

\begin{tabular}{|c|c|c|c|c|c|c|c|c|}
\hline & Frequency (MHz) & 859 & 925 & 1920 & 2045 & 2300 & 2450 & 2600 \\
\hline Distance & Input power (dBm) & 24 & 24 & 21 & 21 & 21 & 21 & 21 \\
\hline $\mathrm{d}=5 \mathrm{~mm}$ & 1 g SAR (W/kg) & 1.37 & 1.43 & 0.798 & 0.813 & 0.795 & 0.793 & 0.819 \\
\hline $\mathrm{d}=5 \mathrm{~mm}$ & $10 \mathrm{~g} \mathrm{SAR}(\mathrm{W} / \mathrm{kg})$ & 0.877 & 0.924 & 0.448 & 0.437 & 0.418 & 0.404 & 0.437 \\
\hline $\mathrm{d}=10 \mathrm{~mm}$ & $1 \mathrm{~g} \mathrm{SAR}(\mathrm{W} / \mathrm{kg})$ & 1.09 & 1.13 & 0.794 & 0.789 & 0.710 & 0.679 & 0.678 \\
\hline $\mathrm{d}=10 \mathrm{~mm}$ & $10 \mathrm{~g} \mathrm{SAR}(\mathrm{W} / \mathrm{kg})$ & 0.706 & 0.74 & 0.409 & 0.395 & 0.357 & 0.343 & 0.356 \\
\hline $\mathrm{d}=20 \mathrm{~mm}$ & $1 \mathrm{~g} \mathrm{SAR}(\mathrm{W} / \mathrm{kg})$ & 0.702 & 0.733 & 0.619 & 0.576 & 0.444 & 0.405 & 0.420 \\
\hline $\mathrm{d}=20 \mathrm{~mm}$ & 10 g SAR (W/kg) & 0.463 & 0.48 & 0.295 & 0.276 & 0.222 & 0.205 & 0.234 \\
\hline
\end{tabular}

Table VII exhibits the comparison of simulated SAR in $1 \mathrm{~g}$ and $10 \mathrm{~g}$ head tissues, for the proposed antenna placed at the bottom position of the mobile phone, with the presence of the homogenous spherical head model and SAM phantom head with reference antenna [25], for the selected operating frequencies. In this study, two gap distances $\mathrm{d}=5 \mathrm{~mm}$ and $\mathrm{d}=10 \mathrm{~mm}$ between the antenna and the 
phantom head are analyzed. From the table, it is found that the peak $1 \mathrm{~g}$ and $10 \mathrm{~g}$ SARs obtained by simulation, for the proposed antenna, with the presence of the homogenous head and SAM phantom head are close to each other. In addition, by comparing the peak SARs for the two SAM phantoms, it is clearly seen that the proposed antenna shows a lower SAR values in comparison to published work. Furthermore, from the obtained results listed in Table VI and Table VII, we conclude that the homogenous spherical head and SAM phantom head produce higher SAR than the HUGO human head model.

TABLE VII. COMPARISON OF SIMULATED SAR IN ONE GRAM AND TEN GRAMS HEAD TISSUES, FOR THE PROPOSED ANTENNA PLACED AT THE BOTTOM POSITION OF THE MOBILE PHONE, WITH THE PRESENCE OF THE HOMOGENOUS HEAD AND SAM PHANTOM HEAD WITH REFERENCE ANTENNA [25]; TWO GAP DISTANCES 5 MILLIMETER AND 10 MILLIMETER BETWEEN THE ANTENNA AND THE PHANTOM HEAD ARE INVESTIGATED

\begin{tabular}{|c|c|c|c|c|c|c|c|}
\hline \multirow[b]{2}{*}{ Head } & \multirow{2}{*}{$\begin{array}{c}\text { Input power } \\
(\mathrm{dBm})\end{array}$} & \multicolumn{4}{|c|}{ Present work } & \multicolumn{2}{|c|}{ Published work [25] } \\
\hline & & \multicolumn{2}{|c|}{ Homogenous } & \multicolumn{2}{|c|}{ SAM phantom } & \multicolumn{2}{|c|}{ SAM phantom } \\
\hline Distance & & \multicolumn{6}{|c|}{$\mathrm{d}=5 \mathrm{~mm}$} \\
\hline $\begin{array}{l}\text { Frequency } \\
\text { (MHz) }\end{array}$ & - & $\begin{array}{c}\text { SAR }_{1 g} \\
(\mathbf{W} / \mathbf{k g})\end{array}$ & $\begin{array}{l}\text { SAR }_{10 g} \\
(W / k g)\end{array}$ & $\begin{array}{l}\mathbf{S A R}_{1 \mathrm{~g}} \\
(\mathbf{W} / \mathbf{k g})\end{array}$ & $\begin{array}{l}\mathbf{S A R}_{10 g} \\
(\mathrm{~W} / \mathrm{kg})\end{array}$ & $\begin{array}{c}\text { SAR }_{1 \mathrm{~g}} \\
(\mathrm{~W} / \mathrm{kg})\end{array}$ & $\begin{array}{l}\text { SAR }_{10 g} \\
(W / k g)\end{array}$ \\
\hline 859 & 24 & 1.84 & 1.36 & 1.88 & 1.36 & 2.04 & 1.43 \\
\hline 925 & 24 & 2.09 & 1.51 & 2.08 & 1.48 & 2.03 & 1.32 \\
\hline 1920 & 21 & 1.64 & 0.966 & 1.36 & 0.829 & 1.58 & 0.97 \\
\hline 2045 & 21 & 1.46 & 0.855 & 1.33 & 0.787 & 1.37 & 0.86 \\
\hline 2300 & 21 & 1.39 & 0.754 & 1.42 & 0.78 & $*$ & $*$ \\
\hline 2450 & 21 & 1.36 & 0.711 & 1.50 & 0.791 & $*$ & $*$ \\
\hline 2600 & 21 & 1.22 & 0.614 & 1.48 & 0.755 & $*$ & $*$ \\
\hline Distance & & \multicolumn{6}{|c|}{$\mathrm{d}=10 \mathrm{~mm}$} \\
\hline 859 & 24 & 1.34 & 1.00 & 1.38 & 1.04 & 1.43 & 1.02 \\
\hline 925 & 24 & 1.49 & 1.10 & 1.48 & 1.10 & 1.53 & 1.07 \\
\hline 1920 & 21 & 1.05 & 0.635 & 0.908 & 0.564 & 0.96 & 0.62 \\
\hline 2045 & 21 & 0.908 & 0.546 & 0.843 & 0.513 & 0.92 & 0.57 \\
\hline 2300 & 21 & 0.854 & 0.476 & 0.827 & 0.479 & $*$ & $*$ \\
\hline 2450 & 21 & 0.868 & 0.468 & 0.864 & 0.49 & $*$ & $*$ \\
\hline 2600 & 21 & 0.845 & 0.439 & 0.869 & 0.483 & $*$ & $*$ \\
\hline
\end{tabular}

\section{CONCLUSION}

This paper presented the results of analysis and investigation of the effects of electromagnetic radiation, measured in terms of the SAR within a human head model exposed to the non-ionizing radiation emitted from an internal planar monopole antenna to be used in LTE, WWAN and WLAN devices. Calculation of SAR has been carried out using commercially available software Ansfot HFSS and CST MWS.The effect of the gap distance between the antenna and the human head model (homogenous spherical head, spherical seven layer model, SAM phantom and HUGO human head model) on the SAR distributions within the human head, at the selected operating frequencies of 859 MHz, 900 MHz, 925 MHz,1900 MHz,1920 MHz,2045 MHz, 2100 MHz,2300 MHz, $2400 \mathrm{MHz}, 2450 \mathrm{MHz}, 2500 \mathrm{MHz}$ and $2600 \mathrm{MHz}$ is systematically evaluated. The SAR levels for the head tissues are calculated in accordance to the two currently accepted standards: FCC $(1.6 \mathrm{~W} / \mathrm{kg}$ for the $1 \mathrm{~g}$ head tissue) and ICNIRP( $2 \mathrm{~W} / \mathrm{kg}$ for the $10 \mathrm{~g}$ head tissue). Moreover, the SAR values of the proposed antenna, placed at the top and bottom positions of the mobile phone, have also been 
discussed. The different positions with respect to the planar monopole antenna and the different dielectric proprieties (conductivity and relative permittivity), imply that the tissues do not experience the same power absorption. Finally, the SAR values obtained from this study indicate that it is promising for the appropriate for the antenna to be placed at the bottom position of the mobile phone, to achieve low SAR values in practical applications.

\section{REFERENCES}

[1] Chen, Z. N., and Chia, M. Y. W: Broadband planar antennas: design and applications. Hoboken: John Wiley \& Son (2006).

[2] Chen, Z., Ban, Y. L., Chen, J. H., Li, J. L. W., and Wu, Y. J., "Bandwidth enhancement of LTE/WWAN printed mobile phone antenna using slotted ground structure," Progress In Electromagnetics Research, vol.129, pp. 469-483, 2012.

[3] Ban, Y. L., Chen, J. H., Li, J. W., and Hu, W., "Printed multi-resonant antenna embedding two inductors in radiating strips for internal mobile phone LTE/WWAN operation," Journal of Electromagnetic Waves and Applications, vol.26, no. (17-18), pp.2211-2221, 2012.

[4] Kusuma, A. H., Sheta, A. F., Elshafiey, I. M., Siddiqui, Z., Alkanhal, M. A., Aldosari, S., and Mahmoud, S. F., “A new low SAR antenna structure for wireless handset applications," Progress In Electromagnetics Research, vol.112, pp. 2340, 2011.

[5] Islam, M. T., Faruque, M. R. I., and Misran, N., "Reduction of specific absorption rate (SAR) in the human head with ferrite material and metamaterial," Progress In Electromagnetics Research C, vol.9, pp. 47-58, 2009.

[6] IEEE C95.1-2005, "IEEE standards for safety levels with respect to human exposure to radio frequency electromagnetic fields, $3 \mathrm{kHz}$ to $300 \mathrm{GHz}$," Institute of Electrical and Electronics Engineers, New York, NY, 2005.

[7] International Non-Ionizing Radiation Committee of the International Radiation Protectio Association, "Guidelines on limits on exposure to radio frequency electromagnetic fields in the frequency range from $100 \mathrm{kHz}$ to $300 \mathrm{GHz}$," Health Physics, vol. 54, no. 1, pp.115-123, 1988.

[8] Jung, M., Lee, B, "SAR reduction for mobile phones based on analysis of EM absorbing material characteristics," IEEE International Symposium on Antennas and Propagation, vol. 2, pp. 1017-1020, 2003.

[9] Khalatbari, S., Sardari, D., Mirzaee, A. A., and Sadafi, H. A, "Calculating SAR in two models of the human head exposed to mobile phones radiations at 900 and $1800 \mathrm{MHz}$," PIERS Online, vol.2.no.1, pp.104-109, 2006.

[10] Hirata, A., Shirai, K., and Fujiwara, O, “On averaging mass of SAR correlating with temperature elevation due to a dipole antenna," Progress In Electromagnetics Research, vol.84, pp. 221-237, 2008.

[11] Saraereh, O. A., M. Jayawardene, P. McEvoy, and J. C. Vardaxoglou, "Simulation and experimental SAR and efficiency study for a dual-band PIFA handset antenna (GSM 900/DCS 1800) at varied distance from a phantom head," IEE Antenna Measurements and SAR, pp.5-8, 2004.

[12] Kivekas, O., J. Ollikainen, T. Lehtiniemi, and P. Vainikainen, "Bandwidth, SAR, and efficiency of internal mobile phone antennas," IEEE Trans. Electromagn. Compat., vol. 46, no. 1, pp.71-86, 2004.

[13] Wang, J., Fujiwara, O., and Takagi,T.,"Effects of ferrite sheet attachment to portable telephone in reducing electromagnetic absorption in human head," In Electromagnetic Compatibility, 1999 IEEE International Symposium on IEEE ,vol. 2, pp. 822-825, 1999.

[14] Jianqing, W. A. N. G., and Fujiwara, O., "Reduction of electromagnetic absorption in the human head for portable telephones by a ferrite sheet attachment," IEICE Transactions on Communications, vol.80, no.12, pp.1810-1815, 1997.

[15] Kwak, S.I., Sim, D. U., and Kwon, J. H., "Design of optimized multilayer PIFA with the EBG structure for SAR reduction in mobile applications," IEEE transactions on electromagnetic compatibility, vol.53, no.2, pp.325-331, 2011.

[16] Kwak, S.I., Sim, D. U., and Kwon, J. H., "SAR reduction on a mobile phone antenna using the EBG structures," in Proc. 38th Eur. Microw. Conf., Oct. pp. 1308-1311, 2008.

[17] Gómez-Villanueva, R., Jardón-Aguilar, H., and y Miranda, R. L.," State of the art methods for low SAR antenna implementation," In Proceedings of the Fourth European Conference on Antennas and Propagation. IEEE, pp. 1-4, 2010.

[18] Sánchez-Hernández, D. A.: High frequency electromagnetic dosimetry. Artech House, 2009.

[19] Ebrahimi-Ganjeh, M. A., Attari, A. R, "Interaction of dual band helical and PIFA handset antennas with human head and hand," Progress In Electromagnetics Research, vol. 77, pp. 225-242,2007.

[20] "IEEE recommended practice for determining the peak spatial-average Specific Absorption Rate (SAR) in the human head from wireless communications devices: measurement techniques," IEEE Standard 1528TM-2003, 2003.

[21] Adair, E.R. and R.C.Peterson, "Biological effects of radiofrequency/microwave radiation," IEEE Trans. MTT, vol.50, no.3, pp.953-961, 2002.

[22] "IEEE Recommended Practice for Determining the Peak Spatial-Average Specific Absorption Rate (SAR) in the Human Head from Wireless Communications Devices: Measurement Techniques," IEEE Standard 1528TM-2013, 2013

[23] L. Belrhiti, F. Riouch , A. Tribak , J. Terhzaz and A.S. Mediavilla, "Calculating the SAR Distribution in Two Human Head Models Exposed to Printed Antenna with Coupling Feed for GSM/UMTS/LTE/WLAN Operation in the Mobile Phone," International Journal of Microwave and Optical Technology, vol. 11, pp.391-398,2016.

[24] http://transition.fcc.gov/oet/rfsafety/dielectric.html.

[25] C. H. Chang and K. L.Wong, "Bandwidth enhancement of internal WWAN antenna using an inductively coupled plate in the small-size mobile phone", Microwave and Optical Technology Letters, vol.52, no.6, pp.1247-1253, 2010. 